\title{
Ibiza Absolute Calibration Experiment: Survey and Preliminary Results
}

J.J. MARTINEZ-BENJAMIN

M. MARTINEZ-GARCIA

S. GONZALEZ LOPEZ

A. NUÑEZ ANDRES

F. BUILL POZUELO

M. ESPINO INFANTES

J. LOPEZ-MARCO

Universitat Politecnica de Catalunya (UPC), Barcelona, Spain

J. MARTIN DAVILA

J. GARATE PASQUIN

C. GARCIA SILVA

Real Instituto y Observatorio de la Armada en San Fernando (ROA), Cadiz, Spain

P. BONNEFOND

O. LAURAIN

Observatoire de la Côte d'Azur/GEMINI (OCA-GEMINI), Grasse, France

A.M. BARON ISANTA

M.A. ORTIZ CASTELLON

J. TALAYA LOPEZ

Institut Cartografic de Catalunya (ICC), Barcelona, Spain

B. PEREZ GOMEZ

E. ALVAREZ FANJUL

Puertos del Estado (PE), Madrid, Spain

G. RODRIGUEZ VELASCO

Universidad Complutense de Madrid (UCM), Spain

D. GOMIS

M. MARCOS

IMEDEA (Universitat de les Illes Balears - CSIC), Palma de Mallorca, Spain 


\section{Y. MENARD}

Centre National d'Etudes Spatiales (CNES), Toulouse, France

G. JAN

E. JEANSOU

Noveltis, Toulouse, France

F. LYARD

L. ROBLOU

LEGOS (Laboratoire d'Etudes en Géophysique et Océanographie Spatiales), Toulouse, France

Keywords altimeter calibration, geoid, GPS buoy, kinematic GPS

\section{Acknowledgments}

The IBIZA 2003 experience has been developed within the framework of the Spanish National R+D Project in Space Research (Ministerio de Ciencia y Tecnologia), ref: ESP2001-4534-PE. Special thanks to the Estado Mayor de la Armada (Ministerio de Defensa), to ROA and to Deva CN. Enrique Rodriguez de Santiago and its crew. Special thanks for the French support. My best thanks to Marta Sastre, Miriam Moysset and Anna Serrano, from the ICC for the support for the Ibiza campaign. GPS (SANB) and tide gauge data from Ibiza and San Antonio were obtained also within the framework of the ESEAS-RI EU project under contract EVR1-CT-2002-40025. 


\begin{abstract}
Within the framework of a project comprising part of the Spanish Space Program related to the JASON-1 CNES (Centre National d'Etudes Spatiales)/NASA (National Aeronautics and Space Administration) mission, a campaign was conducted on June 9-17, 2003, in the Absolute Calibration Site of the island of Ibiza. The objective was to determine the local marine geoid slope under the ascending (187) and descending (248) Jason-1 ground tracks, in order to allow a better extrapolation of the open-ocean altimetric data with on-shore tide gauge locations, and thereby improve the overall precision of the calibration process. For this we have used a catamaran with two GPS antennas onboard, following the Corsica/Senetosa design (Bonnefond et al., 2003a). Five GPS reference stations were deployed in order to reduce the distance between the areas covered by the catamaran and the fixed GPS receiver used in the kinematic process. The geodetic activities (e.g., GPS, leveling) have enabled to build a very accurate (few $\mathrm{mm}$ ) network in a reference frame compatible with the satellite altimetry missions (ITRF2000). The GPS kinematic data were processed using two different softwares allowing to check the consistency of the solutions. If the standard deviation of the differences $(3.3 \mathrm{~cm})$ is close to the kinematic process precision they exhibits some large values (up to $14 \mathrm{~cm}$ ). These large discrepancies have been reduced using a weighting based on the crossover differences. Inasmuch the distances between the tide gauges and the areas covered by the GPS catamaran we have used the MOG2D ocean model (Carrère and Lyard, 2003) to correct the sea surface from tides: in the farest areas it shows an improvement by a factor of two on the crossover differences. Finally, we also present preliminary results on Jason-1 altimeter calibration using the derived marine geoid: from this analysis the altimeter bias is estimated to be $120 \pm 5 \mathrm{~mm}$. The quality of this first result validate the whole GPS-based marine geoid processing, for which the accuracy is estimated to be better than $3 \mathrm{~cm}$ rms at crossovers.
\end{abstract}

\title{
Introduction
}

\section{Description of the Ibiza 2003 campaign}

The Jason-1 project has set up a CalVal Plan organizing calibration and validation activities during the validation and operational phase of Jason-1. Amongst the studies concerning the verification of the altimetric system components, some of them are devoted to the altimeter sea-level measurement assessment by comparing space-derived measurements to in situ ones.

The Jason-1 project has already equipped two main NASA and CNES devoted calibration sites: at the Senetosa Cape in Corsica for the French side (Bonnefond et al., 2003b), and on the Harvest Oil platform off the Californian coast for the USA side (Haines et al., 2003). Other sites are already equipped, or in installation phase for in situ measurements mainly using tide gauges, in order to help the verification of altimeter range measurements. This is the case for Bass Strait, Tasmania (Australia) (Watson et al.,2003), Gavdos Island (Greece) (Pavlis et al.,2002), Lake Eire (USA) (Shum et al.,2003) and Ibiza/ Cape of Begur (Spain).

A Spanish (with French support) JASON-1 calibration campaign, IBIZA 2003, was carried out in June 9-17, 2003 around Ibiza in the NW Mediterranean Sea (Figure 1a). It has required a deep involvement and logistics in the field campaign, in the processing of the collected GPS/tide gauges data and in the analysis of results. The main objective of the campaign was to map the instantaneous sea level/local geoid gradient in three areas around Ibiza: at the crossing point of ascending and descending JASON-1 tracks located to the north of the island, and along these tracks to the SE and SW of the Island (Figure 1b). The campaign was based on the experience gained from three previous pilot experiments at Begur Cape (NE Spain). They were carried out in March 1999 and July 2000 for TOPEX/POSEIDON and August 2002 for JASON-1, as part of the JASON-1 CalVal Team. The Spanish 1999 campaign using a GPS buoy (Born et. al. 1994; Kruizinga, 1997) included the first direct absolute altimeter calibration of TOPEX Altimeter Site B in the western Mediterranean (Martinez-Benjamin et al. 2000). Single point calibrations were performed (Martinez-Garcia et al., 2002). GPS buoys presents potential application to deep-sea studies (Colombo et al., 2000).

A major component of the campaign was a newly designed, calibrated GPS catamaran built up at ICC, following the original design from Senetosa experiences (Bonnefond et al., 2003a). It was towed by the Spanish Navy Patrol Deva, with a crew of 17 persons on board plus researchers from ROA, UPC and 
GEMINI. A zodiac from the Spanish Navy was also used to deploy one light wave-rider GPS buoy at Ibiza and San Antonio harbours. The objective was to provide instantaneous geocentric sea-level measurements with the instantaneous nearby GPS data obtained with the catamaran (an optical levelling was carried out in both harbours). Finally, a direct altimeter absolute calibration was also made (on June 14) with the catamaran and the GPS buoy near the crossover point located to the north of the island.

Complementary data come from five GPS reference stations deployed at Ibiza city, San Antonio and Portinatx, and from vertically-referenced tide gauges located at Ibiza and San Antonio. The marine geoid will be used to relate the coastal tide gauge data from Ibiza and San Antonio harbours to off-shore altimetric data. The map obtained will be used to validate and filter altimetric data in the vicinity of the island and to correct the altimeter data from the geoid slope before comparison with tide gauge measurements.
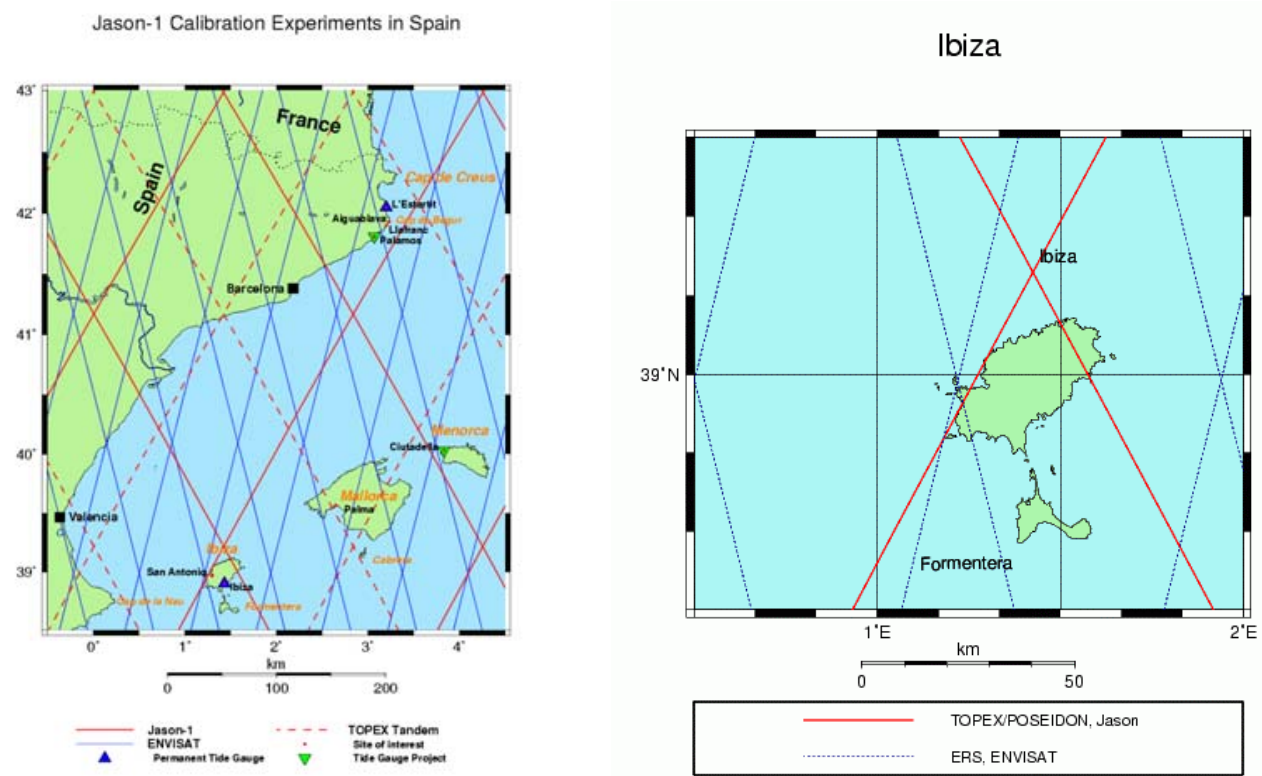

FIGURE 1. Geographical area of the western Mediterranean sea (a) and Ibiza 2003 campaign (b).

\section{Geodetic Characteristics of the Ibiza Island Area}

The Western Mediterranean is quite a complex area for different reasons: due to the presence of several islands, coastal lines, shallow waters and a peculiar hydrologic equilibrium due to its proximity to the Atlantic water exchange area. This makes the estimation of the gravity field and the geoid slope quite a difficult task. Presently there are several global models accounting for free air gravity anomalies (GAS), but their fits are not good enough to make accurate determinations.

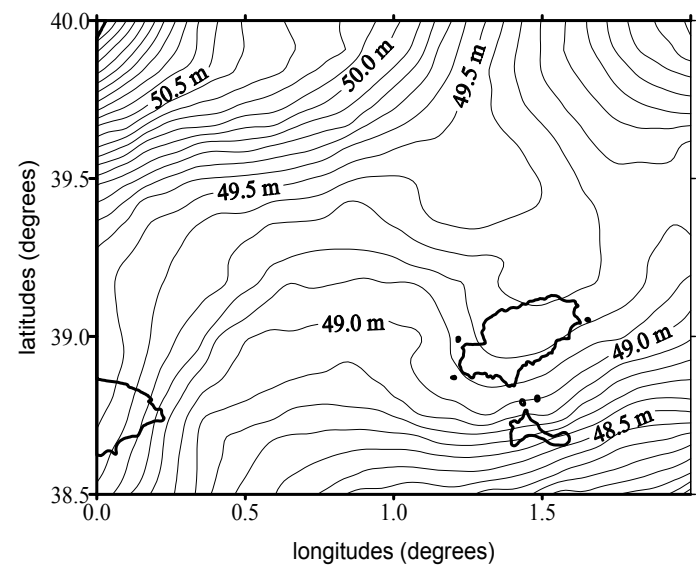

FIGURE 2. Level lines of the gravimetric geoid. Contour interval: $10 \mathrm{~cm}$. 
There are some results for the local/regional gravimetric geoid, which have been built up using different techniques such as least squares collocation (LSC) and spectral methodology (fast Fourier transform; Rodriguez\&Sevilla 2000). In all cases, the classical remove-restore technique has been employed, taking into account the long wavelength part of the gravity field by means of coefficients sets of the geopotential EGM96 model and the topography effect or contribution of high frequencies to the gravity field. The result is a fairly smooth surface, with variation range around the Island of about one meter, from 48,5 m to 49,5 m. The isolines of this geoid are depicted in Figure 2. When gravimetric geoids are compared to each other they show a good match, with only small discrepancies found to the South of Ibiza Island.

\section{The instruments and the data set}

\section{GPS Reference Stations}

Five GPS reference stations were deployed on Ibiza Island: one in Portinatx, two in San Antonio and two in Ibiza (see Figure 1 and Tables 1 and 2). An additional Trimble antenna and receiver were also installed in Ibiza harbour for a few hours (on 06/16/2004). For IBIA, SANA and SANB stations, the raw data set covered 6 days (11-16 June 2003), whereas for IBIB and PORT stations it covered only 5 days. The sample rate was fixed to 30 seconds except during the Catamaran/Buoy measurements, when it was set to 1 second.

TABLE 1 Location and time of observation for each GPS station.

\begin{tabular}{llll}
\hline Marker Name & Location & From & To \\
\hline IBIA & Ibiza (hotel roof) & $11 / 0618 \mathrm{~h} 58$ & $16 / 0624 \mathrm{~h} 00$ \\
IBIB & Ibiza (hotel roof) & $12 / 0608 \mathrm{~h} 29$ & $16 / 0624 \mathrm{~h} 00$ \\
SANA & San Antonio (nautical club roof) & $11 / 0612 \mathrm{~h} 49$ & $16 / 0607 \mathrm{~h} 53$ \\
SANB & San Antonio (nautical club roof) & $11 / 0613 \mathrm{~h} 24$ & $16 / 0607 \mathrm{~h} 32$ \\
PORT & Portinatx (room roof) & $10 / 0615 \mathrm{~h} 49$ & $15 / 0624 \mathrm{~h} 00$ \\
Buoy & Ibiza, San Antonio, Calibration (North) & $11 / 0615 \mathrm{~h} 33$ & $16 / 0607 \mathrm{~h} 37$ \\
CATR & Ibiza, San Antonio, Calibration (North) & $11 / 0615 \mathrm{~h} 34$ & $16 / 0607 \mathrm{~h} 37$ \\
CATL & Ibiza, San Antonio, Calibration (North) & $12 / 0608 \mathrm{~h} 24$ & $16 / 0609 \mathrm{~h} 48$ \\
\hline${ }^{*}$ Dat
\end{tabular}

*Data lacking on 11/06 from 08h09 to end of day

TABLE 2 Antenna height, type of antenna and type of receiver for each GPS station.

\begin{tabular}{lcll}
\hline Marker Name & ARP Height & Antenna Type & Receiver Type \\
\hline IBIA & 0.8447 & TRIMBLE: 4000 ST/SST & ASHTECH: XII Z-12 \\
IBIB & 1.1510 & LEICA: AT502 & LEICA: SR530 3.02 \\
SANA & 0.6385 & ASHTECH: Choke Ring & ASHTECH: iCGRS Z-12 \\
SANB & 0.1438 & TOPCON choke ring antenna CR-3 & TOPCON: LEGACY-E L1/L2 \\
PORT & 0.9510 & LEICA: AT502 & LEICA: SR530 3.02 \\
Buoy $^{*}$ & -0.0078 & TRIMBLE: Compact L1/L2 & TRIMBLE: 4000SSI \\
CATR $^{*}$ & 0.4640 & LEICA: AT502 & LEICA: SR530 3.02 \\
CATL $^{*}$ & 0.4025 & TRIMBLE: Compact L1/L2 & TRIMBLE: 4000SSI
\end{tabular}

"Height relative to the water line.

\section{Catamaran description}

A catamaran equipped with two GPS antennas to perform continuous sea level measurements at a convenient velocity was built up using two wind-surf boards and a metallic structure onto which the antennas were fixed (Figure 3a). The design followed the model used in Senetosa measurements (Bonnefond et al., 2003a), and is stable enough to be towed by a boat (in this campaign the Patrol Deva P29, from the Spanish Navy, Figure $3 \mathrm{~b}$ ) at a convenient speed without stopping GPS data acquisition. Two radomes for protection were placed above the two GPS antennas, a Trimble (CATL), and a Leica (CATR). Two GPS receivers, Trimble 
and Leica, were used aboard the Deva and linked to the antennas of the catamaran by cables independent of the towing rope at a distance about $30 \mathrm{~m}$. Measurements were made in the harbours of San Antonio and Ibiza, with the catamaran close to the GPS buoy (Figure 3c) and at the same time as tide gauge records.

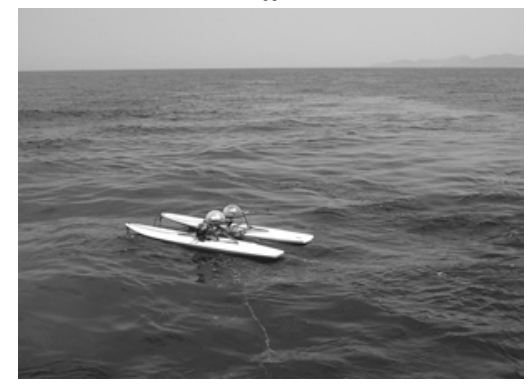

b

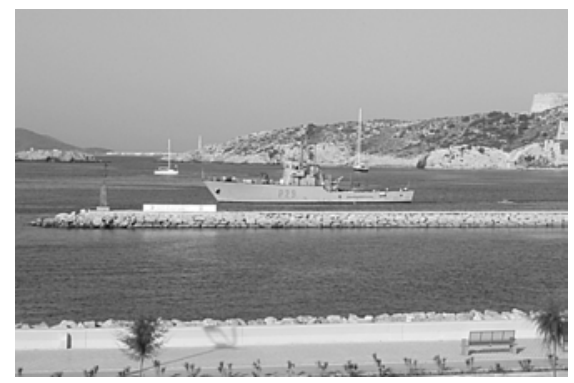

c

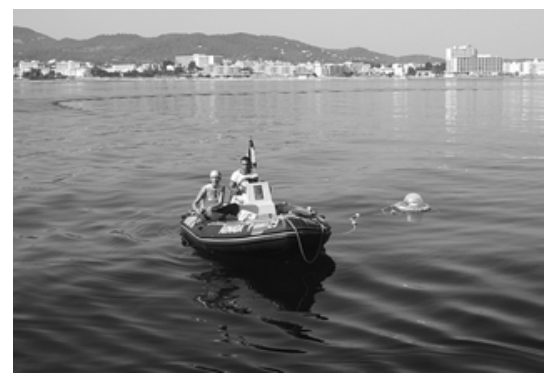

FIGURE 3. GPS Catamaran (a), Patrol Deva from the Spanish Navy towing the GPS Catamaran leaving Ibiza harbour (b) and GPS Buoy near the zodiac at San Antonio harbour (c).

\section{Description of the tide gauges}

The tide gauges used to complement GPS and altimetric data are installed in Ibiza town and San Antonio (see Figure 1 for a general location and Figure 4 for details).

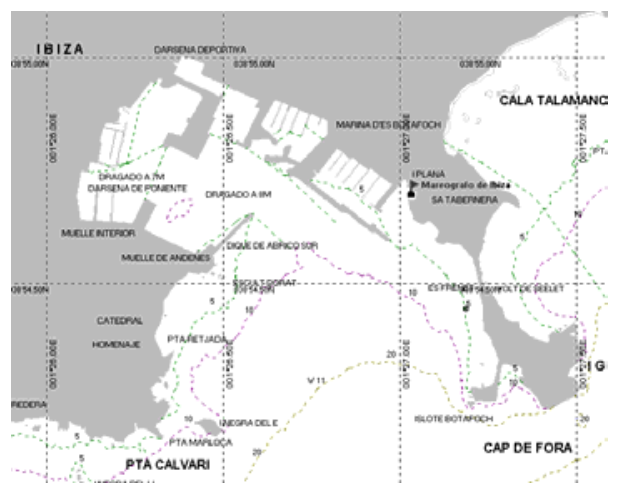

b

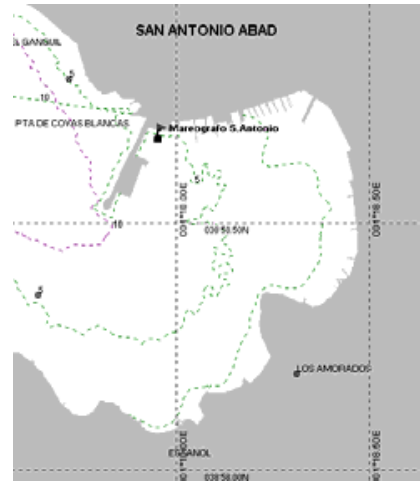

FIGURE 4. Detail of the locations of the tide gauges in Ibiza harbour (a) and San Antonio (b).

The Spanish Port Authority "Puertos del Estado" (hereafter PE) installed the tide gauge station of Ibiza harbour in January 2003. The station is part of the REDMAR network, at this moment comprising 21 stations distributed along the whole Spanish coast (http://www.puertos.es). The tide gauge deployed in Ibiza is also part of the European Sea-Level Service (ESEAS) network. The instrument, an Aanderaa water level/temperature sensor (3796 A) with compensating unit for atmospheric pressure, was installed at the Golondrinas pier (Figure 4a). In 2004 a permanent GPS station funded by ESEAS-RI EU project was placed with the tide gauge in a building in front of the tide gauge pier.

The San Antonio tide gauge (Figure 4b), an Aanderaa WLR7, was deployed by IMEDEA by the beginning of 2002. It was funded by the European Space Agency (ESA) in the framework of the calibration and validation activities of the ENVISAT radar altimeter RA-2. From the beginning of 2003 onwards, the station has been funded by the ESEAS-RI EU Project.

Within the framework of the Ibiza 2003 campaign (on the $1^{\text {st }}$ and $2^{\text {nd }}$ of July 2003), the levelling of both tide gauges to the respective GPS markers was repeated. The classical high precision automatic level Zeiss-Ni1 (with parallel plate micrometer) was used and the method was double run levelling with observation in the middle point to avoid systematic errors. In order to avoid and detect bounder and accidental errors, each line 
was observed twice by the double run method. The loop misclosures in any case exceeded $1 \mathrm{~mm}$. The results are shown in Tables 3 and 4.

TABLE 3. Leveling at San Antonio

\begin{tabular}{|l|c|}
\hline Marker & Height (m) \\
\hline SANA & $8,2431 \pm 0.0008$ \\
\hline SANB & $8,2320 \pm 0.0008$ \\
\hline Top of the iron bar & $0,0000 \pm 0.0008$ \\
\hline Pressure sensor & -1.998 \\
\hline
\end{tabular}

TABLE 4. Leveling at Ibiza

\begin{tabular}{|lc|}
\hline Marker & Height (m) \\
\hline IBIA & $10,5805 \pm 0.0008$ \\
IBIB & $10,5631 \pm 0.0008$ \\
Top of the iron bar & $0,0000 \pm 0.0008$ \\
$\begin{array}{l}\text { Tide Gauge Bench } \\
\text { (TGBM) }\end{array}$ & $0,0001 \pm 0.0008$ \\
\hline Pressure sensor & -0.884 \\
\hline
\end{tabular}

A test for the long term sea level data came has been made from the comparison of sea level measurements recorded at Ibiza and San Antonio with Valencia tide gauge (located on the continental shelf, in front of Ibiza). As shown in Fig.5, the observed evolution of monthly means is largely due to regional meteorological conditions, and is therefore expected to be rather similar for the three stations.

2003 monthly means at Ibiza, San Antonio and Valencia

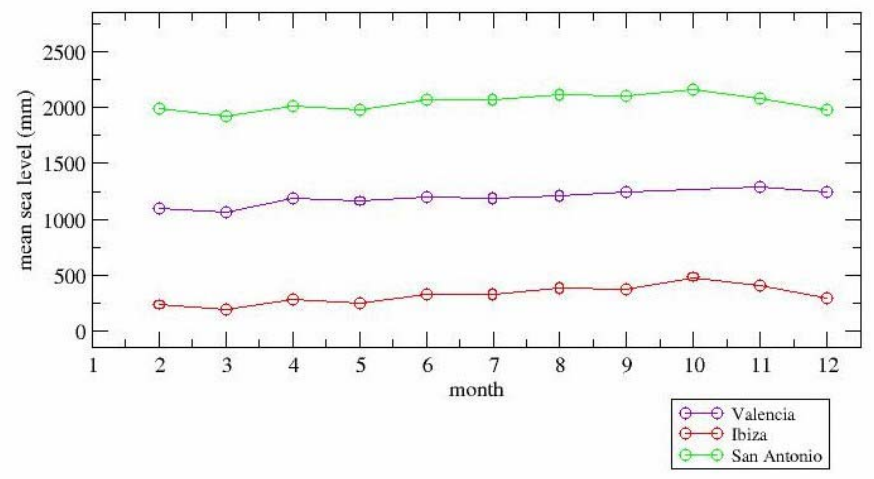

FIGURE 5. Monthly means during 2003 in Valencia, Ibiza and San Antonio tide gauges.

\section{GPS Processing}

The GPS data processing can be divided into two parts: first we need very accurate absolute positions (particularly in the vertical component) in a global reference frame coherent with the one commonly used for T/P and Jason-1 mission (ITRF2000). Secondly, these reference stations will define the datum for the kinematic processing of the GPS catamaran and buoy data but will be also used to determine the absolute sea level heights derived from tide gauges data.

\section{Reference Stations Analysis}

The reference stations are processed using the GAMIT (King and Bock, 2000) and GLOBK (Herring, 2002a) suites developed at the Massachusetts Institute of Technology. Details on the GAMIT/GLOBK processing and standards can be found in Watson et al. (2003).

The GPS station processing has been carried out in two stages: we have used the GAMIT "Relax" mode for the reference stations (SANA, SANB) with antenna compatible IGS standards and the GAMIT "Baseline" mode for the others (IBIA, IBIB, and PORT).

For the two reference stations processed in the GAMIT "Relax" mode, a regional network based on the most accurate GPS stations of the EUREF network has been chosen (Figure 6): Ajaccio and Grasse (France) - 
Cagliari, Matera and Medicina (Italy) - Ebre and San-Fernando (Spain) - Wettzell (Germany). With six daily solutions the weighted root mean square (wrms) values for SANA and SANB were $3.8 \mathrm{~mm}$ and $2.4 \mathrm{~mm}$.

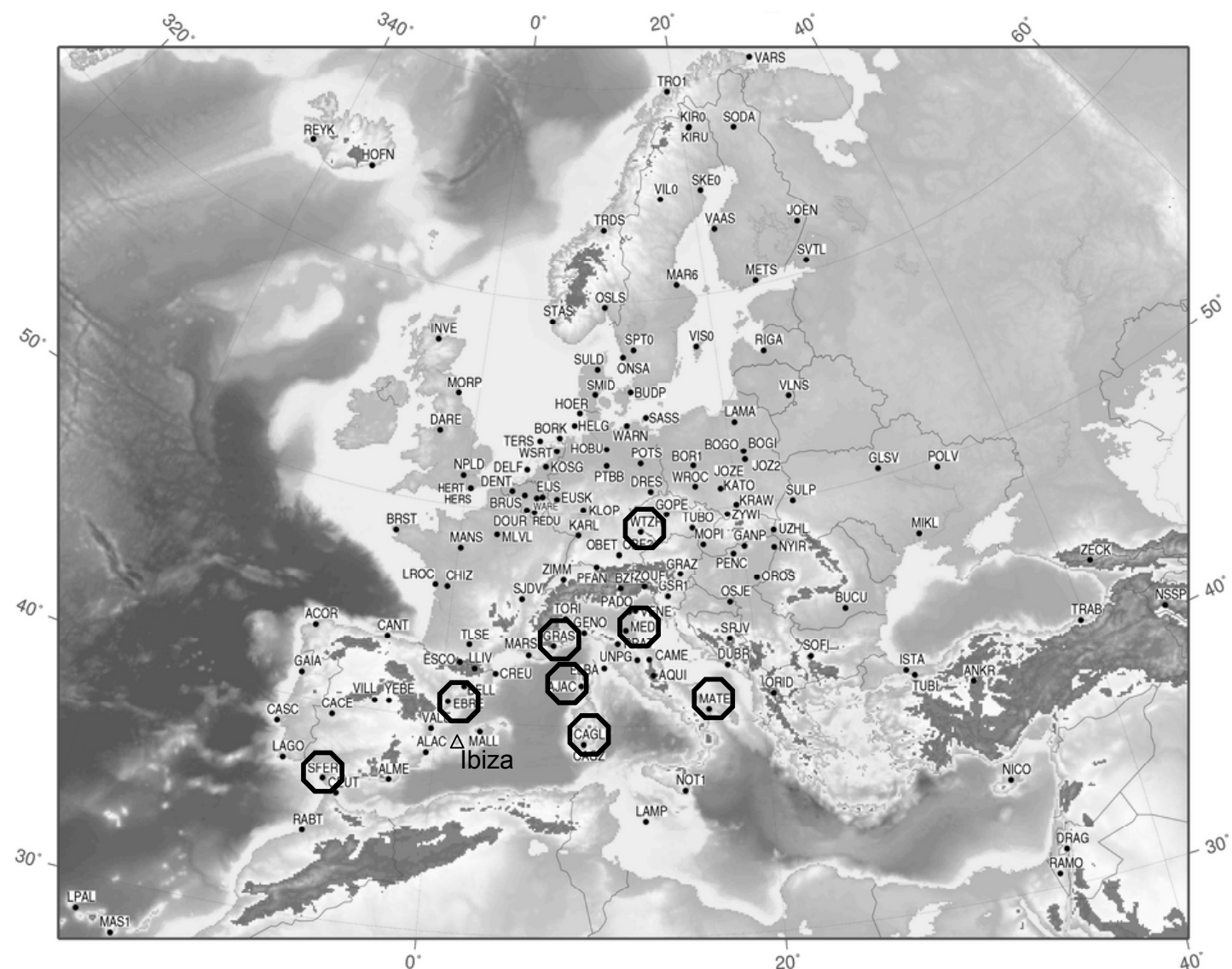

FIGURE 6. Network used for the GAMIT "Relax" mode for SANA and SANB determination.

SANA and SANB were then fixed and the three other stations determined using baselines from these reference stations (GAMIT "Baseline" mode) to reduce the impact of the heterogeneous antenna types. With four daily solutions, the weighted root mean square values for IBIA, IBIB and PORT were $5.0 \mathrm{~mm}, 3.5 \mathrm{~mm}$ and $18.2 \mathrm{~mm}$. The large wrms for PORT is due to a linear trend that remains unexplained at the time of writing. However, because this station is not used as reference station either for kinematic or for tide gauges absolute positioning, the poor determination will have a very small impact.

In order to estimate the quality of the local network used during this campaign we have compared the height differences with the optical leveling (Table 3 and 4). The very good agreement (Table 5) for the reference stations $(2 \mathrm{~mm})$ and the relatively good agreement between the other stations ( $5 \mathrm{~mm}$ for IBIA-IBIB) make us confident as to the quality of the Ibiza network in term of systematic errors: indeed, the reference stations (SANA and SANB) have been processed independently using long baselines from European IGS stations and the others relatively short baselines $(30-40 \mathrm{~km})$ using the SANA and SANB reference stations. Cartesian coordinates of the GPS stations are given in Table 6 at the epoch 2003.456 as well as their heights above the conventional GRS80 ellipsoid used in GPS processing (semi major axis of $6378137 \mathrm{~m}$ and an inverse flattening of 298.257222101).

TABLE 5 Height differences between GPS results and leveling

\begin{tabular}{lccc}
\hline Marker1->Marker2 & $\delta$ H GPS (m) & $\delta$ H Leveling $(\mathbf{m})$ & Difference Leveling - GPS (m) \\
\hline SANA-SANB & -0.013 & -0.011 & +0.002 \\
IBIA-IBIB & -0.012 & -0.017 & -0.005 \\
\hline
\end{tabular}


TABLE 6 Cartesian coordinates and heights above GRS80 ellipsoid at epoch 2003.456

\begin{tabular}{lcccc}
\hline Marker & $\mathbf{X}(\mathbf{m})$ & $\mathbf{Y}(\mathbf{m})$ & $\mathbf{Z}(\mathbf{m})$ & H $(\mathbf{m})$ \\
\hline SANA & 4963596.226 & 112798.208 & 3990492.996 & 57.438 \\
SANB & 4963597.316 & 112793.093 & 3990491.772 & 57.425 \\
PORT & 4953996.022 & 130706.294 & 4001814.258 & 76.430 \\
IBIA & 4968004.124 & 125818.741 & 3984658.110 & 60.311 \\
IBIB & 4968002.892 & 125818.607 & 3984659.621 & 60.299
\end{tabular}

\section{Kinematic Analysis}

The kinematic solutions are based on high rate GPS data $(1 \mathrm{~Hz})$. The mobile receivers (Catamaran and buoy) ellipsoidal heights are solved relatively to the coordinates of the reference stations chosen in the previous section (OCA-GEMINI solution). This processing was carried out independently by ICC (POSGPS Software) and OCA-GEMINI (TRACK software).

\section{Description of Each Solution}

\section{OCA-GEMINI Solution}

The kinematic solution has been processed using TRACK software developed at MIT (Herring 2002b). Details of the TRACK processing and standards can be found in Watson et al. (2003). In order to reduce the impact of distance in the kinematic GPS processing SANA, IBIB and PORT were chosen as reference stations (fixed) and CATL and CATR were processed independently. IBIB has been chosen instead of IBIA because it was equipped with the same antenna/receiver as CATR. However, there were large data gaps for the Leica receiver (CATR) and also lots of satellite lost, so the solution was very difficult to process and results were very uncertain because of too few fixed ambiguities. We then decided to use only the CATL solution for processing the GPS sea level map.

\section{ICC Solution}

For computing GPS kinematic sessions ICC used POSGPS v4.02 software, from Applanix. The computation of each trajectory was done in three steps: a forward filtering (positive in time), a backward filtering (negative in time) and a final combination of the two previous processes (smoothing), assigning weights at each epoch according to certain quality parameters. This software also has the possibility to combine different solutions computed from several GPS permanent stations.

In this way, two preliminary quality controls for the estimated trajectory can be done:

1. Differences between the forward filtering process solution and the backward filtering process solution (nearly independent),

2. Agreement between all trajectories computed using different GPS reference stations.

The strategy adopted in the kinematic processes was the following: for each kinematic receiver (buoy or catamaran), a set of trajectories was computed from 3 or 4 different GPS permanent stations (IBIA, IBIB, PORT, SANA or SANB). The two best trajectories (determined by the quality controls explained before) were combined to obtain a final solution. The combination uses weights that the software assigns to each one, depending on some internal quality parameters (number of satellites, ambiguities fixed, distance from rover to reference station, standard deviation...). We can also force the process not to use one solution in a certain time period (then software gives weight 0 to this one).

The accuracy of trajectories obtained in these processes showed some variability depending on the quality of data collected. For most buoy sessions, some time periods showed a large number of important satellite occlusions as can be observed in Figure 7 showing the number of locked satellites during a session. 


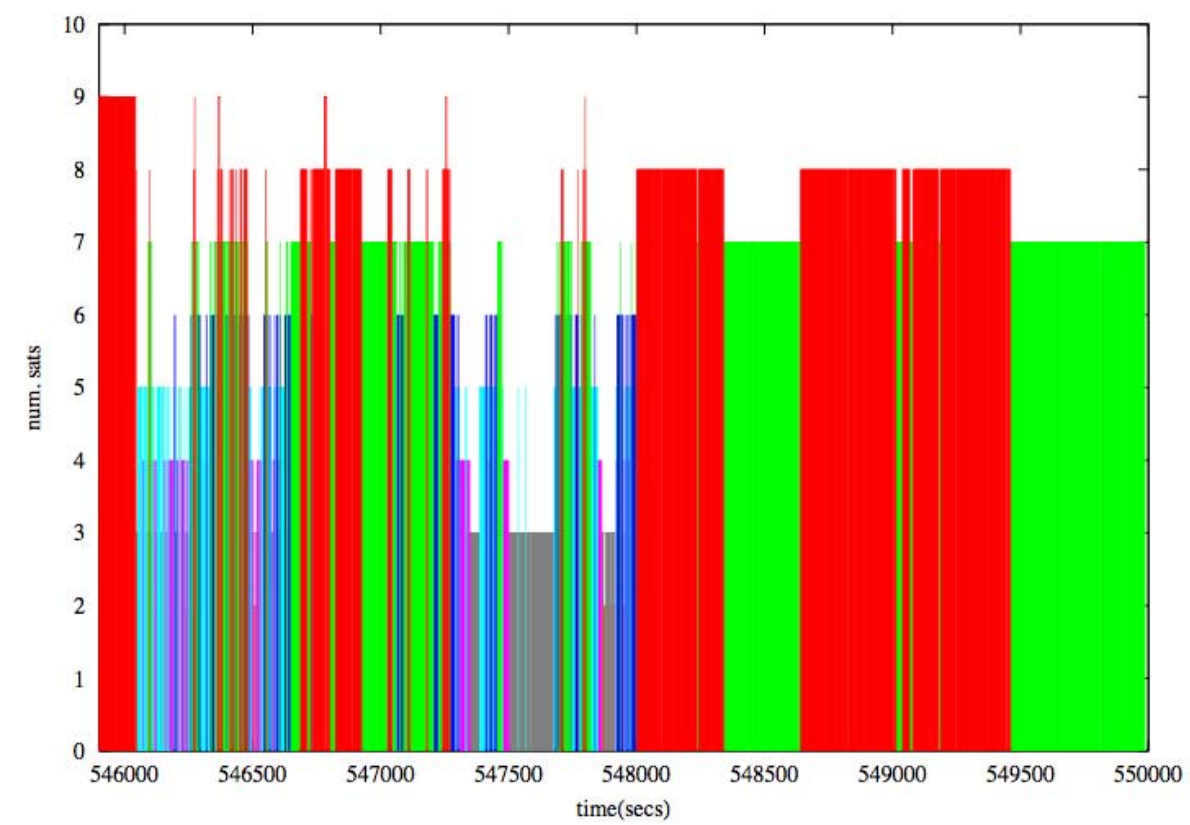

FIGURE 7. Satellite visibility in buoy for day 165 (06/14/2003).

As a consequence, for these periods, no position can be obtained for the buoy, and the data around them was also too bad to obtain acceptable results. Despite this, in time intervals with a good number of satellites (for example from time 548000 to the end of the session in Figure 7), estimated accuracy for buoy trajectory was below a few centimeters. Figure 8, shows the comparison between two solutions of the buoy trajectory computed from two different stations (SANA and SANB stations).

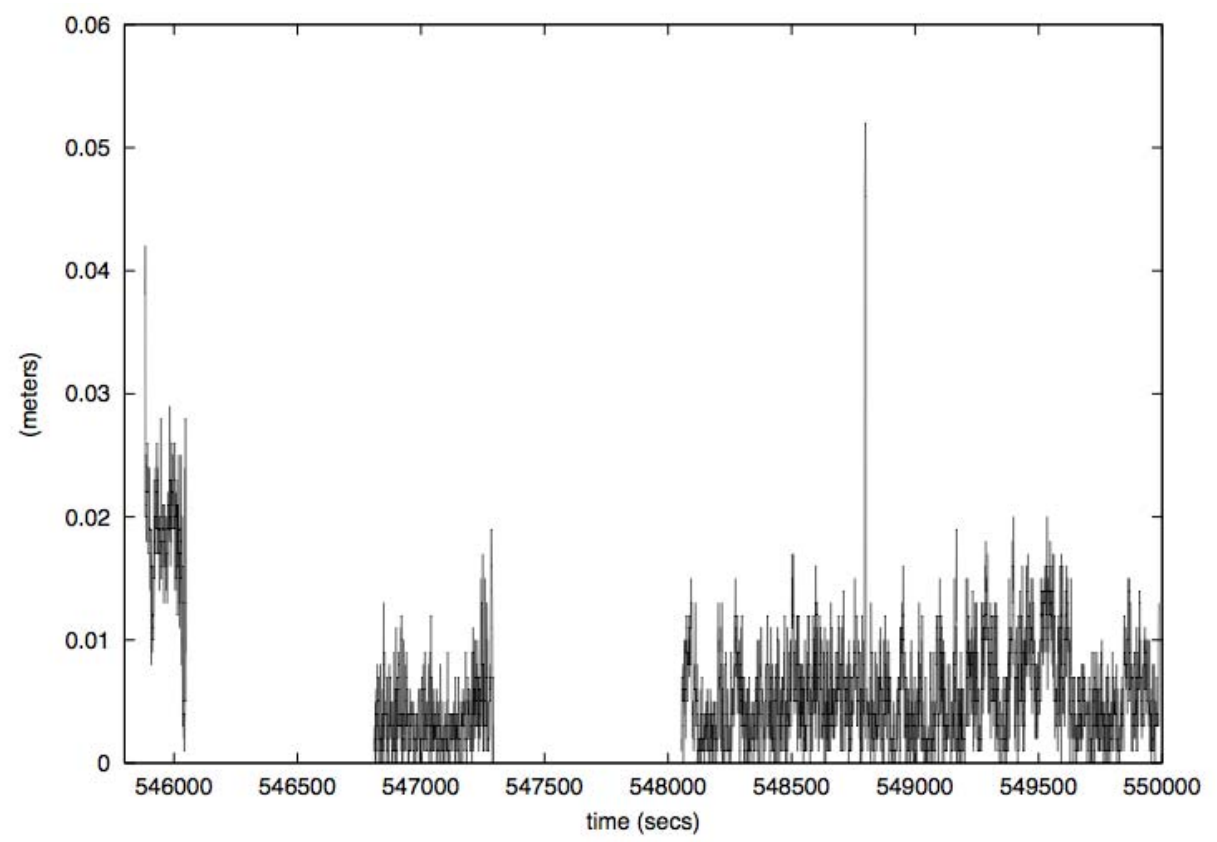

FIGURE 8. Absolute value of height difference between solutions from SANA and from SANB to buoy for day $165(06 / 14 / 2003)$.

For the processes of the kinematic catamaran trajectories, data collection in both receivers also showed some short time intervals with less than 4 satellites (lasting for 3 or 4 seconds) that also caused a poor estimate of the trajectory. Figure 10 shows the difference between forward and backward filtering processes for session 163 of antenna placed in the left side of the catamaran. Some spikes can be observed that were caused by the interruptions of satellite signals (checked observing raw data from receivers). Moreover, there are some persistent differences of up to $20 \mathrm{~cm}$, that may be caused by a faulty resolution of ambiguities in one of the 
processes (after loss of satellites, ambiguities are solved again), taking into account the fact that the distance to the reference station was greater than $20-30 \mathrm{~km}$. It must be noted that the accuracy of the solution might be much better than values shown by these differences imply (one of both processes may be better than the other in some time intervals).

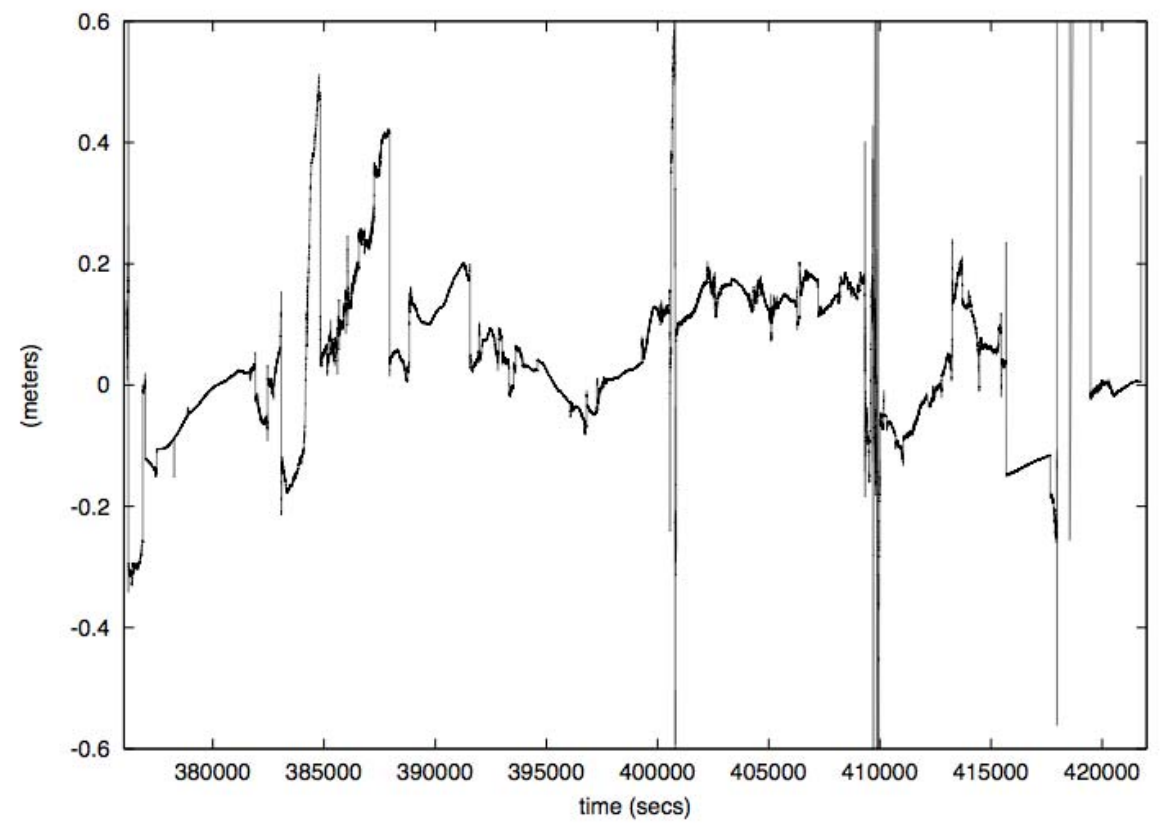

FIGURE 9. Height difference between forward and backward solutions from IBIB to catamaran for day 163 $(06 / 13 / 2003)$.

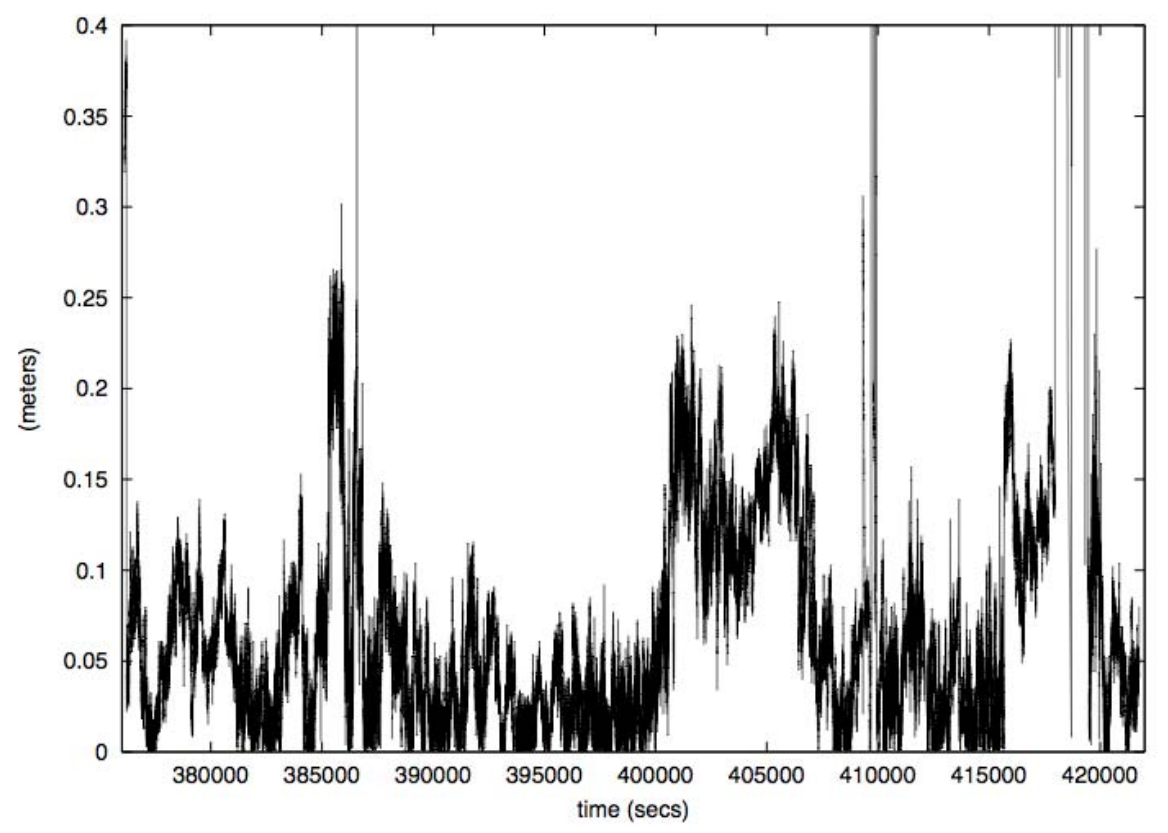

FIGURE 10. Absolute values of height difference between solutions from IBIB and SANA to catamaran for day $163(06 / 12 / 2003)$.

Following Figure 11 shows the differences in the trajectory of this session computed from two different reference stations.

The problems with the data quality previously explained, affected the accuracy of the estimated trajectory. However, it must be noted that the problems are very localized, and despite the existence of some persistent differences (for example up to $15-20 \mathrm{~cm}$ around time 400000 seconds in previous plot), it is well known that 
they are caused by problems in the process from one of the reference stations chosen (in this case from SANA). Then, in the final trajectory, this bad solution is discarded for this time interval. All catamaran kinematic sessions are very long (around 10 hours or more), hence, for the greater part of the trajectories the quality is acceptable (below a few centimeters). Moreover, the final trajectories (combining two solutions computed from different GPS reference stations) allowed a redundancy increase and a quality improvement leading to a final trajectory determination accurate enough for this project's aims. Figure 11 shows the coherence of a catamaran trajectory determination from two GPS reference stations, noting that most of the difference is of around 5-6 cm during the 12.5 hour session.

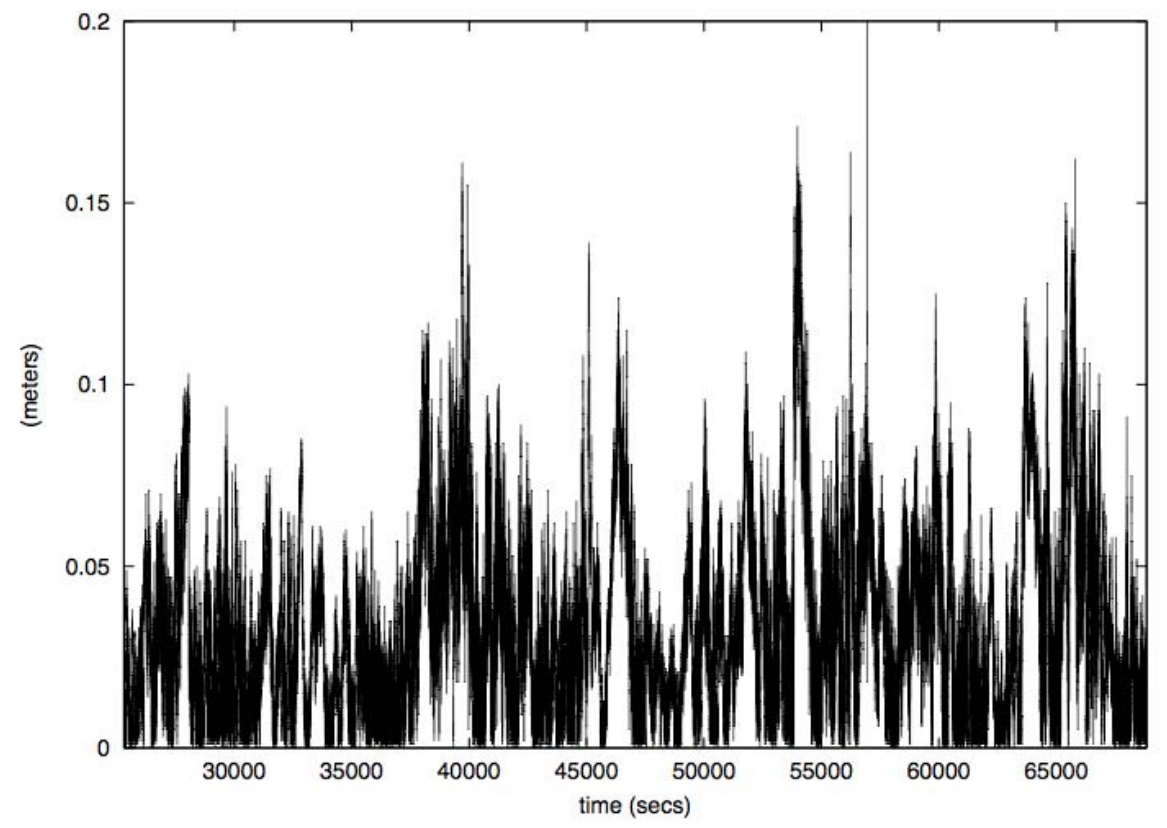

FIGURE 11. Absolutes values of height difference between solutions from IBIB and SANA to catamaran for day $166(06 / 15 / 2003)$.

\section{Sea Height Processing}

Methods and details used to derive the sea level map from kinematic GPS solutions can be found in Bonnefond et al. (2003a). We will only describe the steps and parameters of the processing which are different from the Corsica experiment.

\section{Filtering and Data Editing}

The chosen boat velocity was about $4.2 \mathrm{~m} / \mathrm{s},(\sim 8 \mathrm{knots})$ so the cut-off period in the time domain was chosen as $400 \mathrm{~s}(\sim 1.7 \mathrm{~km}$ in the space domain) in order to homogenize along-track and across-track $(\sim 2 \mathrm{~km})$ wavelengths. This filtering also allows reduction of the high frequency sea level variations due to both GPS processing uncertainty and sea state. Only results on the filtered GPS sea heights are given in this paper.

For the data editing a global velocity criteria (between 3.7 and $4.7 \mathrm{~m} / \mathrm{s}$ ) was chosen in order to avoid speeddependent sea-height variations. Some parts of the solutions were also excluded due to very poor results for both ICC and OCA-GEMINI solution (large crossover values, rms, ...): the longer period removed is for the long diagonal of the south west area because the boat had to be stopped to reinforce the towing rope; in fact during this period the GPS cable was too tense and the connector was unscrewed leading to many satellite loss. From a total of 158400 , only 74505 GPS data was kept for the final solution (Figure 12): the eliminated data mostly corresponds to transits between the harbours and the area of interest (59103 GPS data) during which time the boat velocity was about 10 knots $(\sim 5 \mathrm{~m} / \mathrm{s})$. 


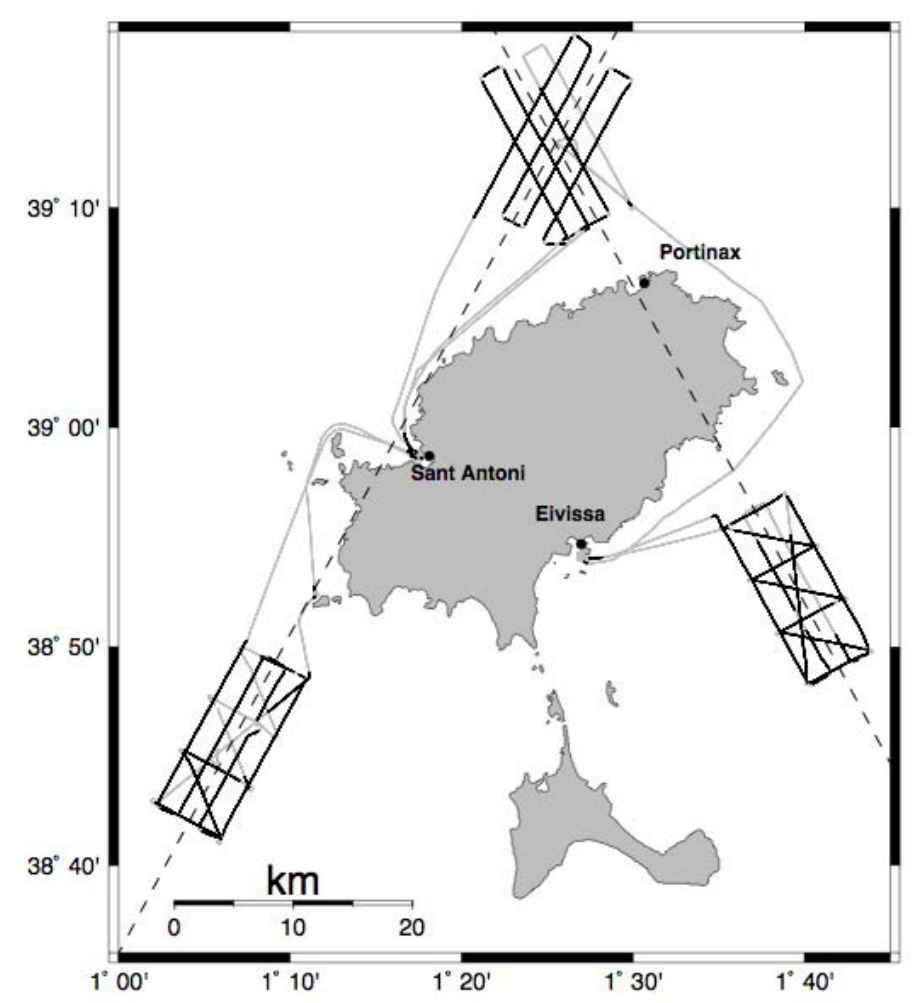

FIGURE 12. GPS data collected (gray) and kept (black). Dashed lines represent the Jason-1 passes: ascending $\mathrm{N}^{\circ} 187$ (South West - North East) and descending N²48 (North West -. South East).

\section{Tide Correction}

Because of the time needed to cover the whole area, it is necessary to correct the instantaneous GPS sea heights for tides. In that way all the sea heights refer to a common reference epoch $(06 / 13 / 2003$ at $12 \mathrm{~h} 00)$ and are then comparable. In Bonnefond et al. (2003a), authors have used tide gauge information for correcting the GPS sea heights. We also used such a method but because of distance between areas of interest and tide gauge locations, significant ocean dynamics can cause this correction to lack accuracy. In order to improve this correction, we used an ocean model (MOG2D): results and comparisons of these two approaches are given in this section.

\section{From Tide Gauges}

The principle of this correction is to compute the sea level height difference between instantaneous tide gauges measurement, at the time of GPS data, and mean sea level at the chosen reference epoch (Table 7). This correction is derived from each tide gauge (Ibiza and San Antonio) and averaged before being applied to GPS sea heights. Figure 13 shows the differences between the San Antonio and Ibiza tide gauges corrections at the GPS data location. From this map we can see that, because Ibiza and San Antonio tidal signals are not in phase, differences can slowly increase (up to $\sim 4 \mathrm{~cm}$ ) during a few hours, and then a deformation in the sea surface at wavelength comparable to the areas size $(15 \mathrm{~km})$ can occur during this period. This is very critical because it can affect the mean geoid slope that is of interest for the altimeter calibration.

TABLE 7 Mean of tide gauges heights from 06/11/2003 (9h00) to 06/17/2003 (0h00) for Ibiza and San Antonio

\begin{tabular}{ccc}
\hline & Ibiza $\left(\mathbf{M}_{\mathbf{1}}\right)$ & San Antonio $\left(\mathbf{M}_{\mathbf{2}}\right)$ \\
\hline Mean height $(\mathrm{m})$ & 49.114 & 49.209 \\
\hline
\end{tabular}

\footnotetext{
Reference epoch: day 164 (06/13/2003) at $12 \mathrm{~h} 00$
} 


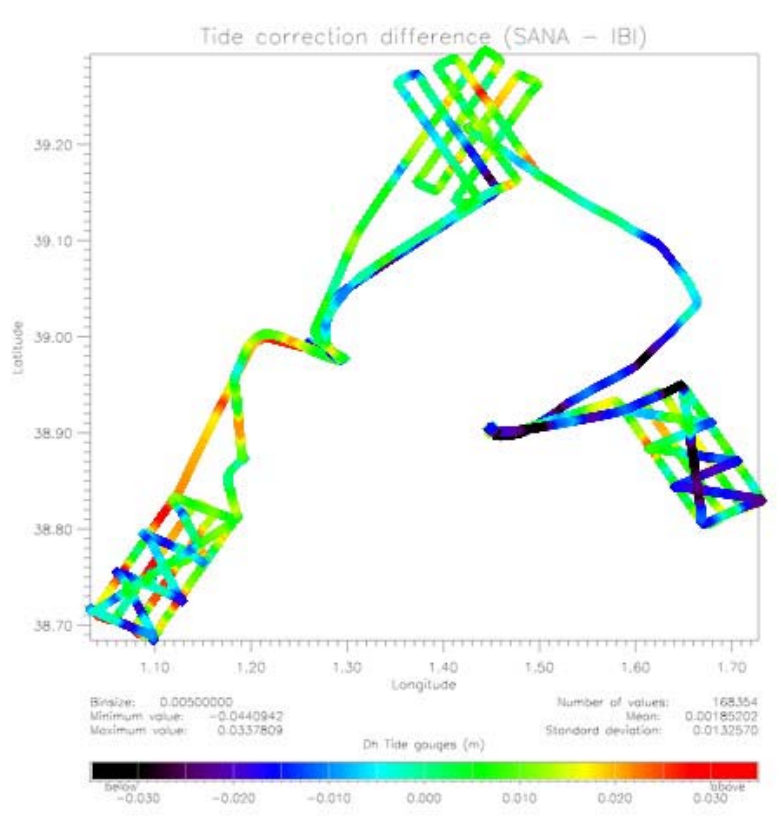

FIGURE 13. Differences between the San Antonio and Ibiza tide gauges corrections at the GPS data location (unit is meters).

\section{From an Ocean Model}

MOG2D is a barotropic, time-stepping, non-linear model, derived from Lynch and Gray (1979) developed at the LEGOS, France. In short, it is based on a wave equation formulation and the non-conservative momentum equations. Forcing terms include the tidal potential (both astronomical and loading/self-attraction parts), the atmospheric surface pressure and wind stress. Dissipative terms include non-linear bottom friction, wave drag parameterization and horizontal diffusion (based on a Smagorinski scheme). One of the most appealing features of this model is its finite element spatial discretisation (Lagrange P1-P1 type) allowing an increase in resolution in coastal areas and over regions of steep topography. In this application, the Mediterranean-MOG2D grid size varies from $30 \mathrm{~km}$ in regions of deep topography to less than $1 \mathrm{~km}$ in some coastal areas (Figure 14). A novel sub-cycling time scheme allows dynamic and local adaptation of the time step to control the model stability instead of tuning the horizontal viscosity terms.

The meteorological forcing is extracted from the cartesian grid products ARPEGE (analysis) and ALADIN (forecasting) from Météo-France operational system. The spatial and time resolutions range from $0.5^{\circ} / \mathrm{six}$ hours (eastern Mediterranean basin) to $0.1 \%$ three hours (western Mediterranean basin). As a consequence, the dynamic processes with a period equal to or less than 6 and 12 hours are misrepresented in the atmospheric forcing and hence in the model simulation. The wind stress is computed from wind speed through the classical bulk formula from Rosati and Miyakoda (1988). Open boundary conditions are taken from the inverted barometer approximation through a radiative condition (characteristics method). Although the influence of the Atlantic ocean on the Mediterranean sea through the Gibraltar strait is limited, later experiments have demonstrated that the impact of inverted barometer-based boundary conditions was not insignificant on the simulations' accuracy. In present applications, this problem is solved by using the global ocean MOG2D simulations (Carrère and Lyard, 2003) as boundary conditions. 


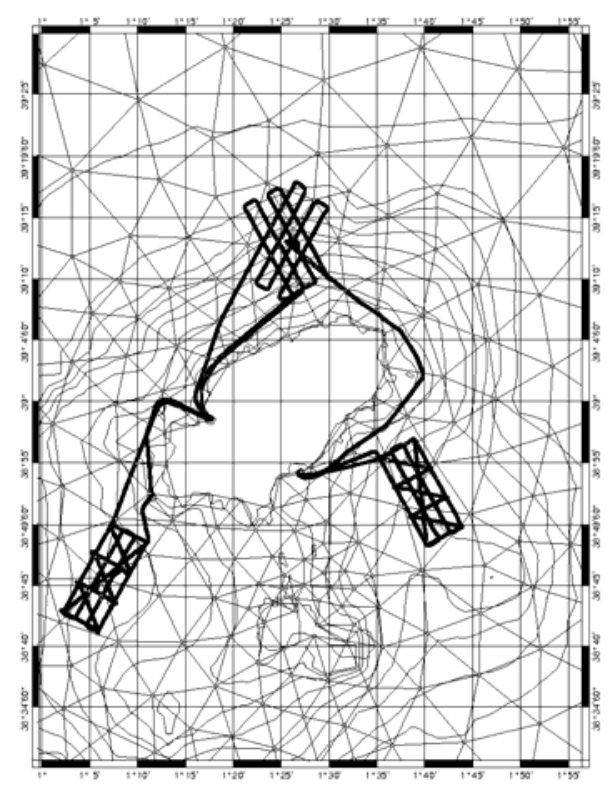

FIGURE 14. Finite element spatial discretisation in the area of Ibiza.

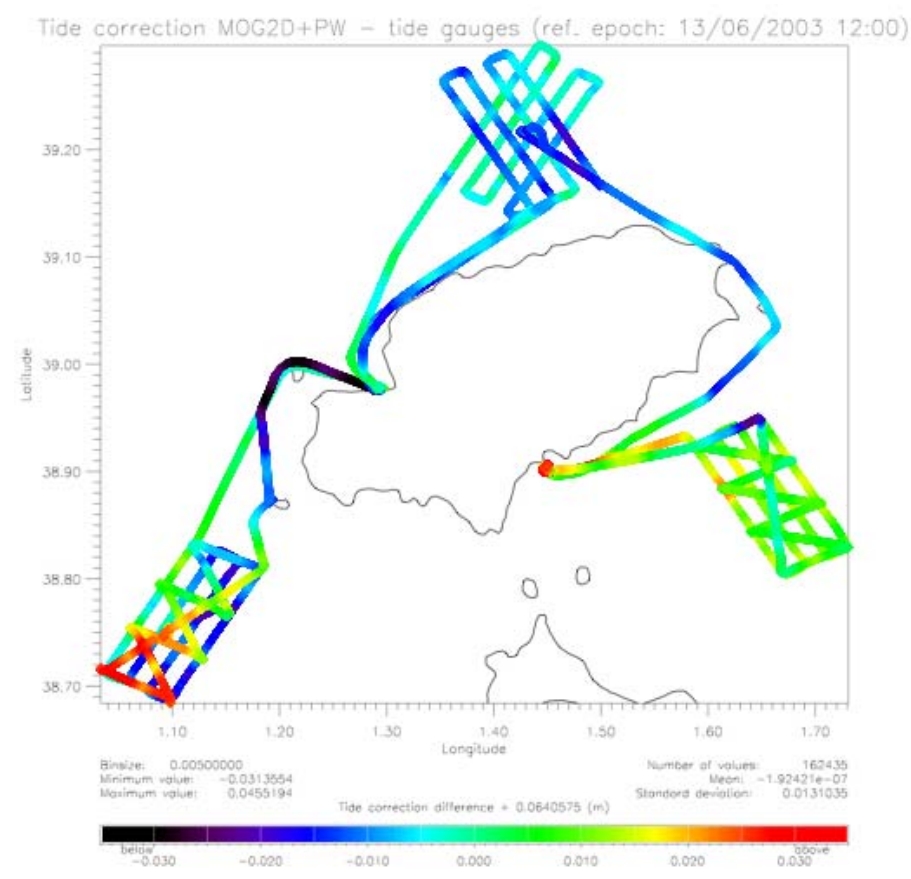

FIGURE 15. Differences between MOG2D and tide gauges approach for tide correction (unit is meters).

To compute the tide corrections a first run of the model was done at each GPS data location with a constant time corresponding to the chose reference epoch (13/06/2003 at 12h00). In a second step the model is run at each GPS data location and time and the difference is used to correct the GPS sea heights. Figure 15 shows the tide correction differences between MOG2D and tide gauges approach; this clearly reveals that in the southern part of the southeast area MOG2D can significantly improve the tide correction. Indeed, it was an area where we found the largest differences for tide gauges (see Figure 13). This is confirmed by the significant decrease of crossover differences (Table 9).

\section{Comparisons of Results}

In this section we will compare the ICC and OCA-GEMINI solutions using internal and external estimators in order to evaluate the quality of both solutions. Results of these comparisons are also given for the two tide correction approaches. 


\section{Internal Consistency}

The crossover differences method has been described in detail in Bonnefond et al. (2003a). Tables 8 to 10 show the statistics for both ICC and OCA-GEMINI solutions, for the South West, South East and North areas. The average standard deviation is close to $4 \mathrm{~cm}$ and $5 \mathrm{~cm}$ respectively for OCA-GEMINI and ICC solutions either for tide gauges or MOG2D correction. From this it is very difficult to analyze the impact of MOG2D because of lots of outliers in the crossovers. These outliers are due to divergence of the solutions either for ICC or OCA-GEMINI for parts of the campaign where lots of satellites were not locked. However because of software behavior differences these parts were not always located at the same place in time or space (Figure 15). So we have decided to merge the two solutions using the crossovers for controlling the process. This method and results are given in the section "Mixing the Solutions".

TABLE 8 Crossover differences for the South West area

\begin{tabular}{lccccc}
\hline Correction & $\mathbf{N}$ & Min $(\mathbf{c m})$ & Max $(\mathbf{c m})$ & Mean $(\mathbf{c m})$ & $\sigma(\mathbf{c m})$ \\
\hline Tide gauges & 44 & -11.4 & 5.7 & -1.5 & 4.4 \\
MOG2D & 44 & -7.1 & 7.5 & 0.5 & 3.9 \\
\hline & & ICC & 16.1 & -0.4 & 5.9 \\
\hline Tide gauges & 46 & -9.9 & 17.4 & 1.6 & 6.3 \\
MOG2D & 46 & -9.1 & & & \\
\hline
\end{tabular}

TABLE 9 Crossover differences for the South East area

\begin{tabular}{lccccc}
\hline Correction & $\mathbf{N}$ & Min $(\mathbf{c m})$ & Max $(\mathbf{c m})$ & Mean $(\mathbf{c m})$ & $\sigma(\mathbf{c m})$ \\
\hline OCA-GEMINI & & & \\
\hline Tide gauges & 80 & -6.4 & 6.2 & 0.0 & 3.0 \\
MOG2D & 80 & -7.1 & 5.8 & -0.7 & 3.0 \\
\hline Tide gauges & 82 & -10.8 & 5.8 & -0.9 & 2.9 \\
MOG2D & 82 & -10.5 & 5.3 & -1.8 & \\
\hline
\end{tabular}

TABLE 10 Crossover differences for the North area

\begin{tabular}{lccccc}
\hline Correction & N & Min $(\mathbf{c m})$ & Max $(\mathbf{c m})$ & Mean $(\mathbf{c m})$ & $\sigma(\mathbf{c m})$ \\
\hline Tide gauges & 39 & -8.3 & 7.8 & -0.2 & 3.4 \\
MOG2D & 39 & -7.7 & 7.3 & -0.7 & 3.6 \\
\hline & & OCA-GEMINI & \\
\hline Tide gauges & 42 & -12.0 & 8.0 & -0.4 & 5.2 \\
MOG2D & 42 & -12.6 & 7.6 & -0.9 & 5.4 \\
\hline
\end{tabular}

\section{External Consistency}

\section{Between Solutions}

Table 11 shows the statistics of the GPS sea height differences between OCA-GEMINI and ICC solutions. If the averaged standard deviation is reasonable $(3.3 \mathrm{~cm})$ compared to the classic noise of kinematic GPS, the minimum/maximum exhibits large values up to $14 \mathrm{~cm}$. As explained before in the crossovers section, this is 
due to a region where OCA-GEMINI or ICC solutions are very bad. These discrepancies are due to the software strategy and the lost of signals which have often occurred during the campaign: indeed, it implies that a new ambiguity has to be defined and search for each data gap and then the solution accuracy is affected. Moreover the distance between the reference stations and the catamaran is a factor of degradation. It means that for short distance and not too often data gap the GEMINI and ICC solutions are very close (see day 11/06 in Table 11).

TABLE 11 GPS sea heights differences for CATL: GEMINI - ICC

\begin{tabular}{llcccc}
\hline Day/Month & Location & Min $(\mathbf{c m})$ & Max $(\mathbf{c m})$ & Mean $(\mathbf{c m})$ & $\sigma(\mathbf{c m})$ \\
\hline $\mathbf{1 1 / 0 6}$ & Bay of San Antonio & -3.2 & 3.2 & 0.0 & 1.6 \\
$\mathbf{1 2 / 0 6}$ & South West area & -11.8 & 13.8 & 0.0 & 4.5 \\
$\mathbf{1 3 / 0 6}$ & North area & -12.0 & 12.0 & 1.6 & 3.6 \\
$\mathbf{1 4 / 0 6}$ & North area & -7.5 & 13.6 & 0.2 & 3.6 \\
$\mathbf{1 5 / 0 6}$ & South East area & -12.4 & 2.9 & -3.1 & 3.0 \\
\hline
\end{tabular}

\section{Tide gauges}

For each day (morning and evening) of the campaign we also made GPS catamaran measurements, and at the same time GPS buoy measurements as close as possible to the tide gauge locations $(<2 \mathrm{~km})$. These measurements were carried out with the same Catamaran velocity as the one used to cover the areas $(4.2 \mathrm{~m} / \mathrm{s})$. These periods were dedicated to comparing sea level with tide measurements, but also to spotting the possible impact of the velocity to the waterline definition for the catamaran (Figure 16). Indeed, the buoy had no velocity, and the antenna height above the waterline was easier to determine. First we should note that on average, results from buoy and Catamaran show similar biases (Table 1). This means that the waterline of the catamaran was well defined. The $1 \mathrm{~cm}$ bias observed at San Antonio is not negligible and might be due either to the absolute height of the tide gauge or the GPS solutions. If such a bias is in the whole GPS solution it will disappear when computing the geoid slope for the altimeter calibration. However, at Ibiza the bias is significantly higher ( $4.8 \mathrm{~cm}$ more than the one observed at San Antonio) so we suspect a problem in the absolute height of the tide gauge. This last point will be discussed and confirmed in the "Preliminary calibration results" section.

TABLE 12 Statistics of the differences between GPS sea heights and tide gauges measurements

\begin{tabular}{lcccc}
\hline Solution & \multicolumn{2}{c}{ Ibiza } & \multicolumn{2}{c}{ San Antonio } \\
\hline & Mean $(\mathbf{c m})$ & $\sigma(\mathbf{c m})$ & Mean $(\mathbf{c m})$ & $\sigma(\mathbf{c m})$ \\
\hline CATL (OCA-GEMINI) & 5.4 & 2.8 & 1.1 & 3.5 \\
CATL (ICC) & 7.1 & 1.7 & 0.5 & 2.5 \\
Buoy (ICC) & 5.8 & 0.7 & 1.6 & 0.6 \\
\hline Average & 6.0 & 2.1 & 1.2 & 1.5 \\
\hline
\end{tabular}




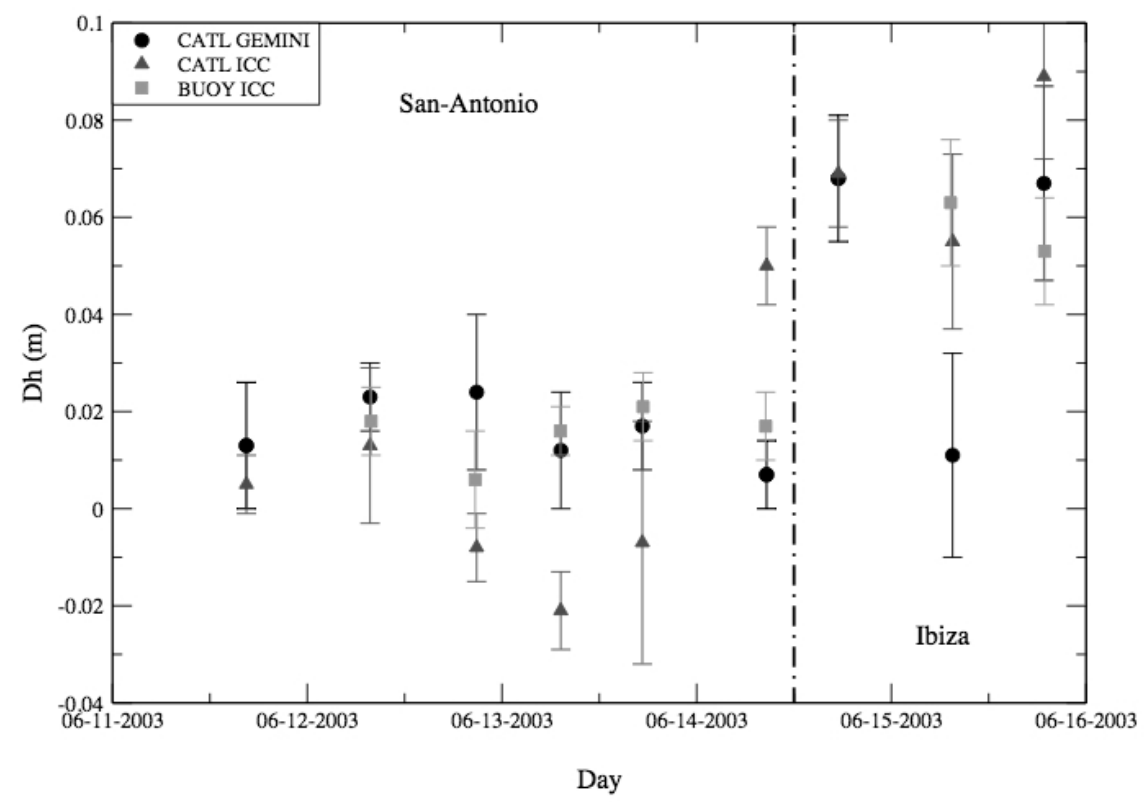

FIGURE 16. Differences between GPS sea heights and tide gauges measurements. Errors bars represent the standard deviation of the differences.

\section{Mixing the Solutions}

The final solution was processed using a weighted average of both ICC and OCA-GEMINI solution based on crossover values. In the first stage, crossovers are interpolated at each time of GPS sea heights and then the following formula is applied.

$\mathrm{H}_{\text {mean }}(\mathrm{t})=\left(\mathrm{H}_{\text {GEMINI }}(\mathrm{t}) * \mathrm{~W}_{\text {GEMINI }}(\mathrm{t})+\mathrm{H}_{\mathrm{ICC}}(\mathrm{t}) * \mathrm{~W}_{\text {ICC }}(\mathrm{t})\right) /\left(\mathrm{W}_{\text {GEMINI }}(\mathrm{t})+\mathrm{H}_{\text {ICC }}(\mathrm{t}) * \mathrm{~W}_{\text {ICC }}(\mathrm{t})\right)$

Where $\mathrm{W}(\mathrm{t})=1 / \mid$ Crossover value interpolated at time $\mathrm{t} \mid$

Figure 17 illustrates this process showing that the mean solution is close to the solution for which the crossovers values are the smallest.

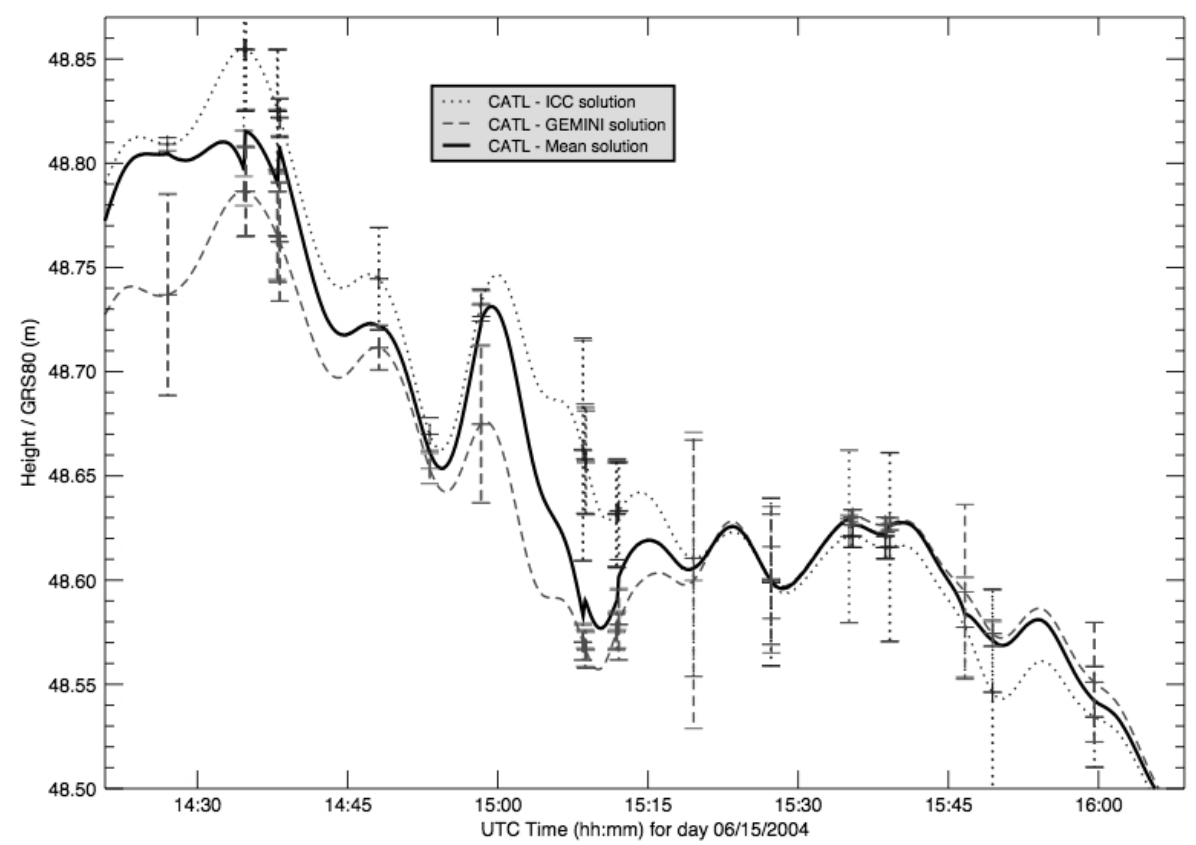

FIGURE 17. Illustration of the weighted average process between OCA-GEMINI and ICC solutions. Error bars represent the crossover values. Dotted, dashed and plain lines are the ICC, OCA-GEMINI and Mean solutions respecttively. 
Tables 13 to 15 show the statistics for the mean solution for the South West, South East and North areas respectively using the MOG2D tide corrections. The standard deviation is reduced from $4-5 \mathrm{~cm}$ (GEMINI and ICC solutions) to $2.7 \mathrm{~cm}$, showing that the mean weighted solution has a better consistency. For the crossovers inside Ibiza and San Antonio bays (close to the tide gauges) the mean is close to zero and they have a standard deviation of $1.5 \mathrm{~cm}$.

TABLE 13 Crossover differences for the South West area

\begin{tabular}{ccccc}
\hline $\mathbf{N}$ & Min $(\mathbf{c m})$ & Max $(\mathbf{c m})$ & Mean $(\mathbf{c m})$ & $\sigma(\mathbf{c m})$ \\
\hline 42 & -7.2 & 8.3 & 1.0 & 2.9 \\
\hline
\end{tabular}

TABLE 14 Crossover differences for the South East area

\begin{tabular}{ccccc}
\hline $\mathbf{N}$ & Min $(\mathbf{c m})$ & Max $(\mathbf{c m})$ & Mean $(\mathbf{c m})$ & $\sigma(\mathbf{c m})$ \\
\hline 79 & -5.6 & 2.1 & -0.9 & 1.9 \\
\hline
\end{tabular}

TABLE 15 Crossover differences for the North area

\begin{tabular}{ccccc}
\hline $\mathbf{N}$ & Min (cm) & Max (cm) & Mean (cm) & $\sigma(\mathbf{c m})$ \\
\hline 38 & -8.1 & 5.2 & -0.9 & 3.2 \\
\hline
\end{tabular}




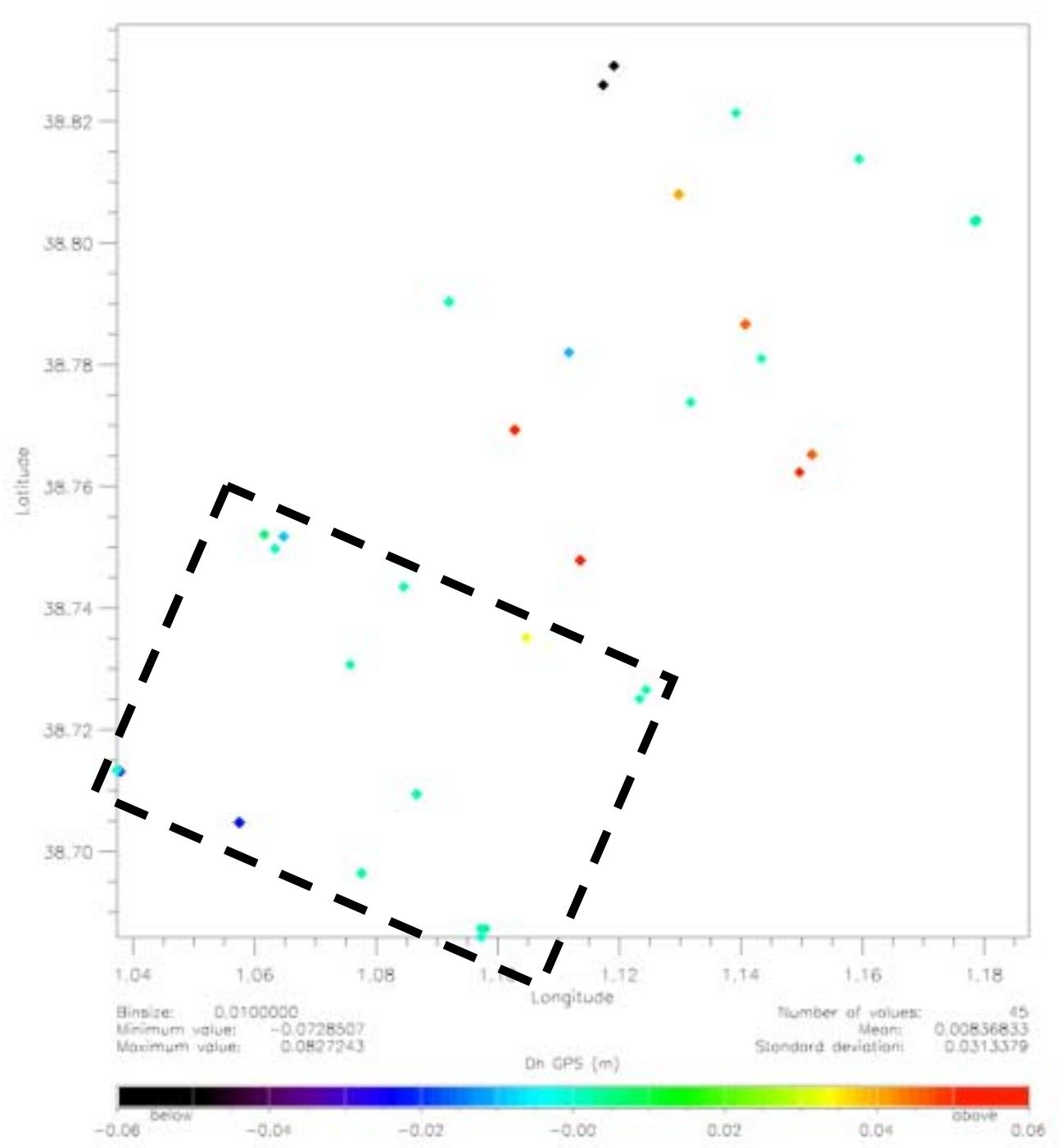

FIGURE 18. Crossovers for the South West areas. The dashed rectangle is the area where the differences between tide gauges and MOG2D tide corrections exhibit the largest differences (unit is meters).

Using the mean weighted solution in the area where tide gauges and MOG2D tide corrections exhibit the largest differences (Figure 18 and 15), the standard deviation of crossovers is reduced by a factor of two, and the mean is close to zero (Table 16). This validates the fact that the use of MOG2D for computing the tide correction is more accurate.

TABLE 16 South West restricted area defined in Figure 18.

\begin{tabular}{lccccc}
\hline Correction & $\mathbf{N}$ & Min $(\mathbf{c m})$ & Max $(\mathbf{c m})$ & Mean $(\mathbf{c m})$ & $\sigma(\mathbf{c m})$ \\
\hline Tide gauges & 20 & -6.0 & 4.7 & -1.7 & 2.4 \\
MOG2D & 20 & -2.5 & 3.2 & -0.3 & 1.2 \\
\hline
\end{tabular}




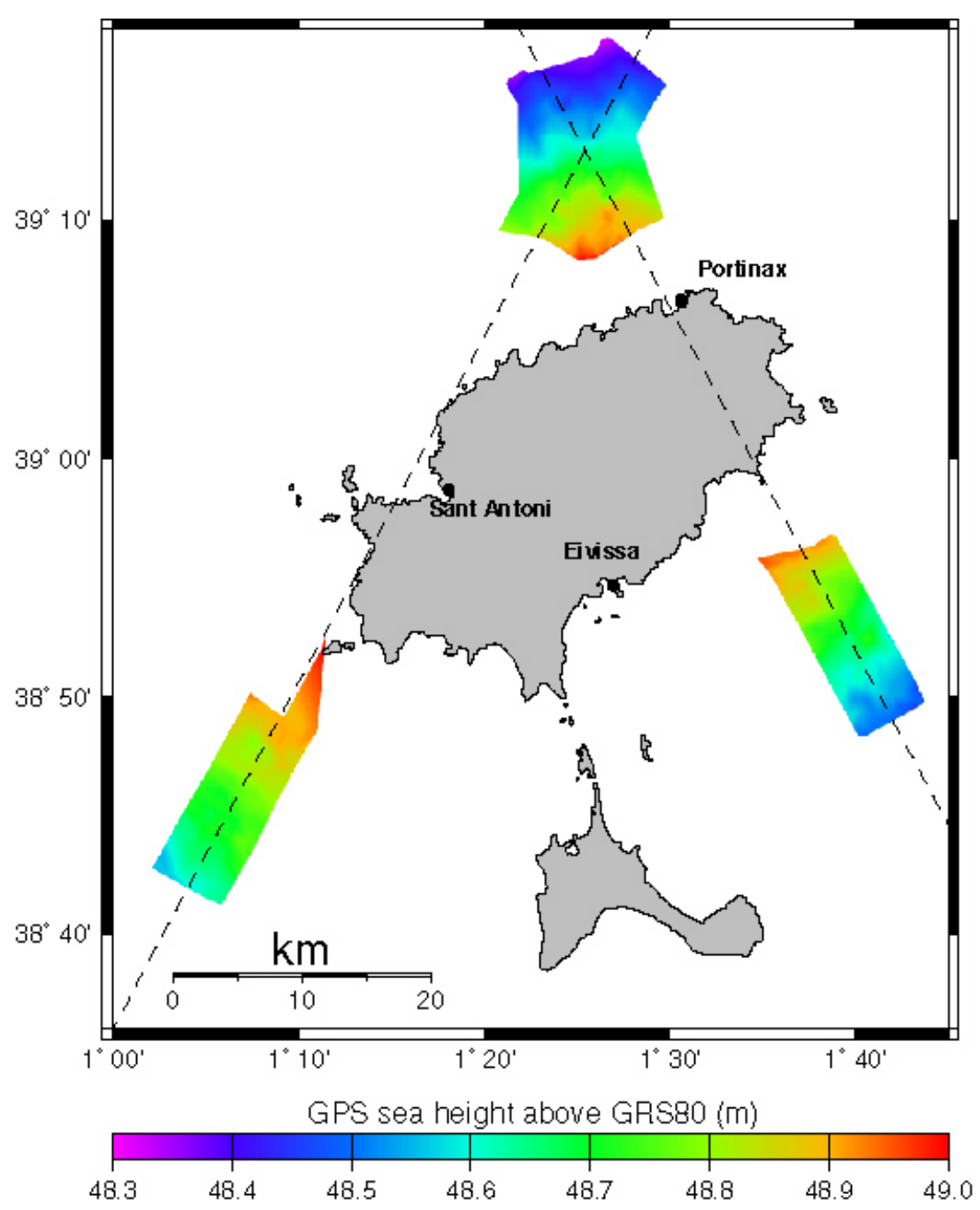

FIGURE 19. Contour Map of the gridded GPS sea surface heights (weighted mean). Dashed lines represent the Jason-1 passes: ascending $N^{\circ} 187$ (South West - North East) and descending $N^{\circ} 248$ (North West -. South East).

The GPS sea surface at the end of the treatment do contain systematic errors (GPS processing, tides model, ...) but this surface is used in a relative sense meaning that it is only used to compute the geoid height differences (the systematic errors cancel out) between altimetric and tide gauge data locations.

\section{Preliminary Calibration Results}

\section{Method}

A comparison of the instantaneous sea surface height ( $\mathrm{SSH}$ ) estimated by two independent techniques at the same geographical location and time was the methodology followed (Bonnefond et al. 2003b). This technique is the so-called direct calibration method. The instantaneous SSH derived from the JASON-1 measurements, that is, the difference between the satellite orbit height $\left(\mathrm{h}_{\text {orbit }}\right)$ and the altimeter measurement $\left(\mathrm{h}_{\mathrm{alt}}\right)$, which represents the corrected basically raw range of the media delays, troposphere and ionosphere, the sea state bias and the instrumental delay:

$$
S S H_{J A S O N}=h_{\text {orbit }}-h_{\text {alt }}
$$

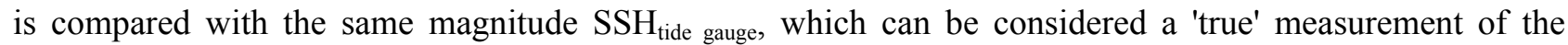
instantaneous sea level, estimated from the measurements of the GPS buoys placed underneath the ascending $\mathrm{T} / \mathrm{P}$ satellite ground track. The bias of the altimeter is obtained from this comparison : 


$$
B I A S=S S H_{J A S O N}-S S H_{\text {tide gauge }}
$$

However, because off-shore altimetric data are affected by the geoid slope, the Sea Level map derived from the GPS catamaran campaign (Figure 19) is used to correct them (Figure 20). Such a method is described in detail in Bonnefond et al. (2003b): the mean catamaran heights at tide gauge locations used to compute the geoid height differences are given in Table 17.

TABLE 17 Mean of GPS sea heights at tide gauge locations

\begin{tabular}{cccc}
\hline \multicolumn{2}{c}{ Ibiza $\left(\mathbf{M}_{\mathbf{1}}\right)$} & \multicolumn{2}{c}{ San Antonio $\left(\mathbf{M}_{\mathbf{2}}\right)$} \\
\hline Mean $(\mathrm{m})$ & $\sigma(\mathrm{m})$ & Mean $(\mathrm{m})$ & $\sigma(\mathrm{m})$ \\
\hline 49.119 & 0.017 & 49.148 & 0.017 \\
\hline
\end{tabular}

JASON-1 POSEIDON-2 - Cycle : 44 - Pass : 248

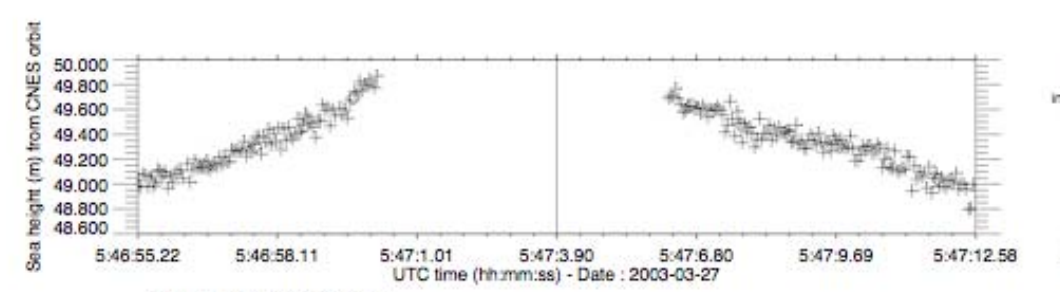

Is resclition data: 0.05 tresoution dath : eliminated anas:

Geoid height (m)
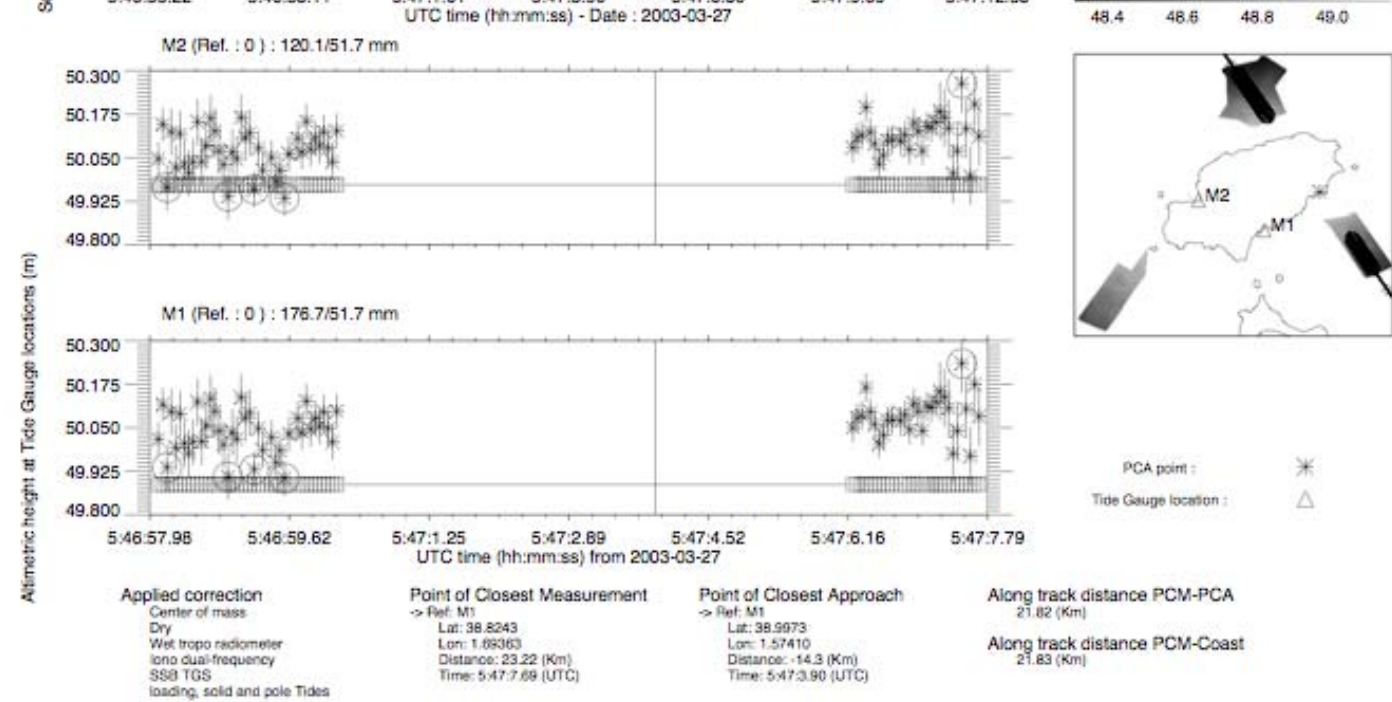

FIGURE 20. Jason-1 altimeter calibration process for pass 248 and cycle 44.

\section{Jason-1 Altimeter Bias}

Jason-1 altimetric data was analyzed from cycle 9 (beginning of San Antonio tide gauges data) to cycle 62 . Figure 21 shows the time series of the Jason-1 altimetric bias for pass 187 (left) and 248 (right) from Ibiza and San Antonio tide gauges 

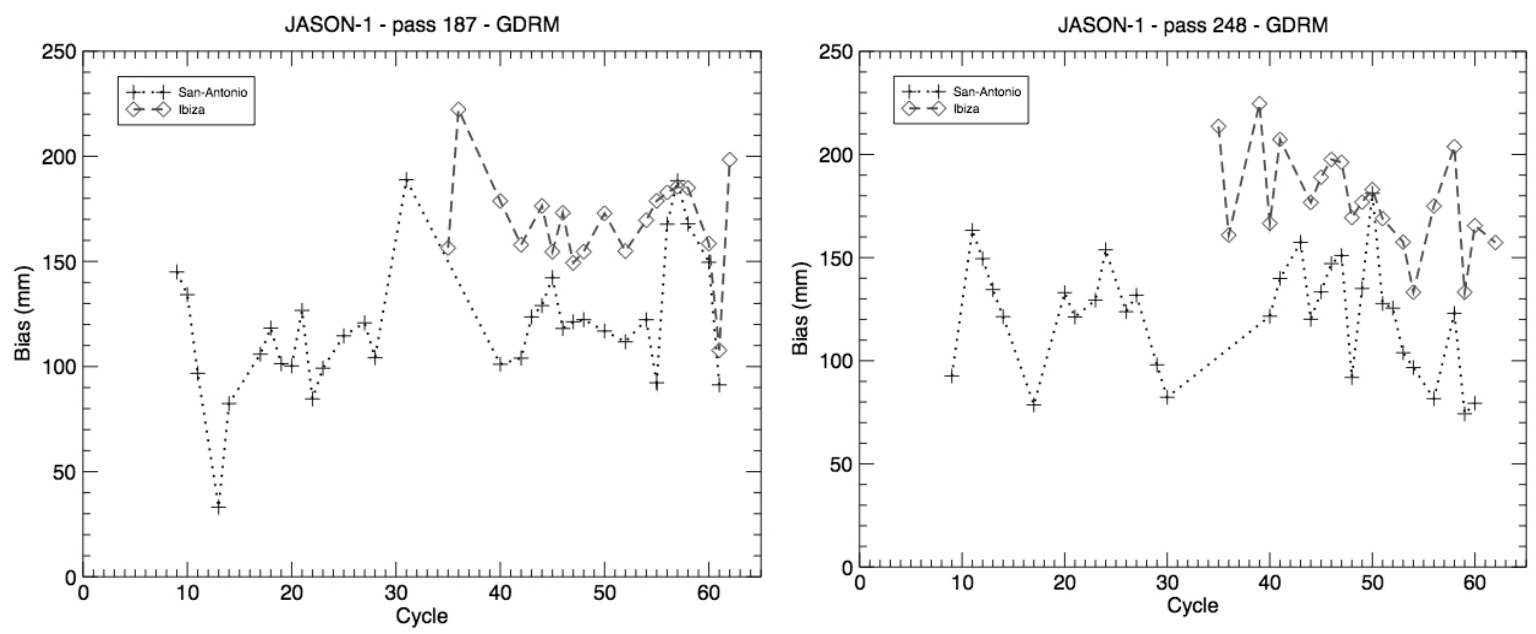

FIGURE 21. Time series of Jason-1 altimeter bias for pass 187 (left) and 248 (right). Crosses and diamonds represent the determination from San Antonio and Ibiza tide gauges respectively.

The statistics of this analysis are summarized in Table 18. The bias found at San Antonio is very close to that found at other calibration sites notably the Corsica one where the geographically correlated errors should be comparable (orbit, sea state,..): $+138 \pm 7 \mathrm{~mm}$ at Harvest (Haines et al., 2003), $+120 \pm 7 \mathrm{~mm}$ at Corsica (Bonnefond et al., 2003b) and $+131 \pm 11 \mathrm{~mm}$ at Bass Strait (Watson et al., 2003). However, the one derived from Ibiza tide gauge data exhibit a difference of about $+50 \mathrm{~mm}$. This confirms the difference of $48 \mathrm{~mm}$ found in the GPS sea height versus tide gauge sea level at Ibiza (Table 12 and Figure 21). Moreover, the mean sea heights of tide gauges (Table 5) exhibits a difference of $95 \mathrm{~mm}$ while the geoid height difference (Figure 2) should be close to $50 \mathrm{~mm}$. It seems that there should be an error of about $50 \mathrm{~mm}$ either in the leveling or the height between the pressure sensor and the Tide Gauge Bench mark (Table 4). These measurements have to be redone to find the error source.

TABLE 18 Statistics of the Jason-1 altimeter bias for passes 187 and 248 using Ibiza and San Antonio tide gauges.

\begin{tabular}{lcccc}
\cline { 2 - 5 } & \multicolumn{2}{c}{ Ibiza } & \multicolumn{2}{c}{ San Antonio } \\
\hline Pass & Mean $(\mathrm{mm})$ & $\sigma(\mathrm{mm})$ & & $\sigma(\mathrm{mm})$ \\
\hline $\mathbf{1 8 7}$ & 169.0 & 33.4 & 119.0 & 23.4 \\
$\mathbf{2 4 8}$ & 177.0 & 24.5 & 122.0 & 27.4 \\
\hline
\end{tabular}

\section{Conclusion}

The main objective was to test the value of Ibiza Island as a possible permanent calibration site in the western Mediterranean Sea, to complement to the Corsica/Senetosa site. Indeed, more dedicated calibration sites, as Ibiza or San Antonio, can help to control the geographically correlated errors that are significant at single sites. Results from the 2003 campaign, with a technical contribution on the design of the GPS buoy and GPS catamaran, indicate the convenience of including this site in the network of altimeter calibration sites. They also suggest that together with other calibration programs it might contribute to a better characterization and understanding of the altimeter bias. However, this will need the carrying out of a few more optimised campaigns with very high geodetic quality GPS equipment deployed at more suitable sites, such as Llentrisca Cape at Ibiza island and Formentera island in order to avoid the long distances of about 20/30 km GPS-area of mapping limiting the possibilities of the kinematic analysis. On the other hand, this campaign has permitted to obtain a very accurate geodetic network with systematic errors below $5 \mathrm{~mm}$.

Leveling the marine sea surface using a GPS catamaran proved to be useful in defining the local marine geoid slope between the coast and offshore area. This allows the application of the kinematic GPS methodology, significantly expanding the geographic coverage of the survey, and mapping the marine sea surface very quickly when towed by a convenient and powerful ship as in this case with Patrol Deva. 
The area covered by the GPS catamaran represents a huge amount of GPS data processed independently by two institutes using two different softwares. Previous campaigns, (Bonnefond et al, 2003a) used tide gauge data to correct the GPS catamaran in their processing to determine a sea level map near the Corsica/Senetosa site. In this analysis, improved results were obtained by using the MOG2D model data on the ocean tide correction notably far from the location of the tide gauges. The overall precision of the resulting "marine geoid" is estimated to be at the level of $3 \mathrm{~cm}$ rms. The remaining systematic errors which can affect the overall surface (e.g. waterline definition of the catamaran) is estimated to be at the centimeter level from comparisons with the buoy and tide gauges data (Table 12); moreover, these systematic errors cancel out when the geoid height differences are computed in the calibration process.

Finally this "marine geoid" has been used in an altimeter calibration process for two Jason-1 passes and two tide gauges location. The Jason-1 altimeter bias derived from San Antonio tide gauge is $+120 \pm 5 \mathrm{~mm}$ : this is very coherent with the other calibration sites in term of absolute value but also for the standard error $\left(\sigma / \sqrt{ } \mathrm{N}_{\text {cycles }}\right)$.

The first results make us confident on the quality of this newly-implemented absolute altimeter calibration site.

\section{References}

Bonnefond, P., P. Exertier, O. Laurain, Y. Menard, A. Orsoni, E. Jeansou, B. Haines, D. Kubitschek, and G. Born. 2003a. Leveling Sea Surface using a GPS catamaran, Marine Geodesy, 26(3-4), 319-334.

Bonnefond, P., P. Exertier, O. Laurain, Y. Menard, A. Orsoni, G. Jan, and E. Jeansou. 2003b. Absolute Calibration of Jason-1 and TOPEX/Poseidon Altimeters in Corsica, Marine Geodesy, 26(3-4), 261-284.

Born, G.H., M.E. Parke, P. Axelrad, K.L. Gold, J. Johnson, K.W. Key and D.G. Kubitscheck. 1994. Calibration of the TOPEX altimeter using a GPS buoy. J. Geophys. Res. 99(C12), 24517-24526.

Carrere L. and F. Lyard, Modelling the barotropic response of the global ocean to atmospheric wind and pressure forcing - comparisons with observations. 2003. Geophys. Res. Letters, In press.

Colombo, O.L., A.G. Evans, M.I. Vigo-Aguiar, J.M. Ferrandiz and J.J. Benjamin. 2000. Long-baseline $(>1000 \mathrm{~km})$, sub-decimeter kinematic positioning of buoys at sea, with potential application to deep-sea studies. Proceedings ION GPS 2000 Meeting, 19-23 September 2000, Salt Lake City, USA.

Dong, D., T. A. Herring, R. W. King. 1998. Estimating regional deformation from a combination of space and terrestrial geodetic data, Journal of Geodesy, 72(4), 200-214.

Haines, B.J., D. Dong, G.H.Born and S.K.Gill. 2003. The Harvest experiment: Monitoring Jason-1 and TOPEX/POSEIDON from a California offshore platform, Marine Geodesy, 26(3-4), 239-259.

Herring, T. A..2002a. Global Kalman filter VLBI and GPS analysis program, Version 10, Massachusetts Institute of Technology, Cambridge.

Herring, T. A.. 2002b. TRACK GPS kinematic positioning program, Version 1.07, Massachusetts Institute of Technology, Cambridge.

King, R. W., and Y. Bock. 2000. Documentation for the GAMIT GPS Analysis Software, Release 10, Massachusetts Institute of Technology, Cambridge.

Kruizinga, G.L. 1997. Validation and applications of satellite radar altimetry. Ph.D. Dissertation, the University of Texas at Austin.

Lynch, D.R. and W.G. Gray. 1979. A wave equation model for finite element tidal computations. Computers and Fluids. 7:207-228.

Martinez-Benjamin, J. J., M. Martinez-Garcia, M. A.Ortiz, J. Talaya, J. Garate, J. M. Davila, J. M. Ferrandiz, M. I. Vigo-Aguiar, B. Perez and E. Alvarez. 2000. The CATALA campaigns: indirect calibration technique 
for ENVISAT altimeter calibration, Proceedings CD-ROM SP-461, 7 pages, ESA ERS-ENVISAT Symposium, 16-20 Oct. 2000, Gothenburg, Sweden.

Martinez-Garcia, M., M.A. Ortiz and J.J. Martinez-Benjamin.2002. Navigation with GPS buoys applied to the calibration of space radar altimeters in the north western Mediterranean sea. Revista del Instituto de Navegacion de España, ISSN 1578-6064, vol.23,17-25.

Ménard, Y., E. Jeansou and P. Vincent. 1994. Calibration of the TOPEX/Poseidon altimeters at Lampedusa : Additional results at Harvest. J. Geophys. Res. 99(C12), 24487-24504.

Pavlis, E.C. and the GAVDOS Team. 2002. Absolute Sea Level Monitoring and Altimeter Calibration at Gavdos, Crete. Proceedings of the Jason-1 SWT Meeting, 10-12 June 2002, Biarritz, France.

Ray, J., D. Dong, Z. Altamini. 2004. IGS references frames: status and future improvements. IGS 2004 Workshop. March $1^{\text {st }}$, Berne, Switzerland.

Rodríguez, G. and M. J. Sevilla. 2000. Geoid Model in the Western Mediterranean Sea. Physics and Chemistry of theEarth (A) 25, n1. pp: 57-62.

Rosati, A., and K. Miyakoda. 1988. A general circulation model for upper ocean simulation. Journal of Physical Oceanography, 18(11), 1601-1626.

Shum, C.K., Y. Yi, K. Cheng, C. Kuo, A. Braun, S. Calmant and D. Chambers. 2003. Calibration of JASON1 Altimeter over Lake Eire, Marine Geodesy, 26(3-4), 335-354.

Tregoning, P. Lambeck, K. Stolz, A. Morgan, P. McClusky, S. van der Beek, P. McQueen, H. Jackson, R. Little, R. Laing, A. and B. Murphy. 1998. "Estimation of current plate motions in Papua New Guinea from Global Positioning System observations”, J. Geophys. Res., 103(BB6) pp12,181-12,204.

Watson C., R. Coleman, N. White, J. Church. and R. Govind. 2003. "Absolute Calibration of TOPEX/Poseidon and Jason-1 using GPS Buoys in Bass Strait,Australia", Marine Geodesy,26(3-4),285-304. 